\title{
Azulene Moiety as Electron Reservoir in Positively Charged Systems; A Short Survey
}

\author{
Alexandru C. Razus
}

check for

updates

Citation: Razus, A.C. Azulene Moiety as Electron Reservoir in Positively Charged Systems; A Short Survey. Symmetry 2021, 13, 526. https://doi.org/10.3390/ sym 13040526

Academic Editor: Anthony Harriman

Received: 12 March 2021

Accepted: 20 March 2021

Published: 24 March 2021

Publisher's Note: MDPI stays neutral with regard to jurisdictional claims in published maps and institutional affiliations.

Copyright: (C) 2021 by the author. Licensee MDPI, Basel, Switzerland. This article is an open access article distributed under the terms and conditions of the Creative Commons Attribution (CC BY) license (https:/ / creativecommons.org/licenses/by/ $4.0 /)$.
"C.D. Nenitzescu" Institute of Organic Chemistry, Romanian Academy, 202 B Spl. Independentei, P.O. Box 35-108, 060023 Bucharest, Romania; acrazus@yahoo.com

\begin{abstract}
The non-alternant aromatic azulene, an isomer of alternant naphthalene, differs from the latter in peculiar properties. The large polarization of the $\pi$-electron system over the seven and five rings gives to azulene electrophile property a pronounced tendency to donate electrons to an acceptor, substituted at azulene 1 position. This paper presents cases in which azulene transfers electrons to a suitable acceptor as methylium ions, positive charged heteroaromatics and examples of neutral molecules that can accept electrons. The proposed product synthesis was outlined and the expected electron transfer was highlighted by analyzing the NMR, UV-Vis spectra and the $\mathrm{pK}_{\mathrm{R}}{ }^{+}$values.
\end{abstract}

Keywords: azulene; methylium ion; heteroaromatics; $\pi$-electron transfer

\section{Introduction}

The stability of organic compounds can be increased or lowered by the presence of $\pi$ electrons and the conjugation of this type of electron can help the stabilization of an electronic system. Very briefly and as a general rule, the stable aromatic $\pi$ electron systems need to be coplanar with an alternating conjugation and must follow Huckel's rule, namely to contain $4 n+2 \pi$ electrons. For the polycyclic aromatic hydrocarbons, the existence of benzenoid sextets is accepted as a key element in the theory of aromaticity (Clar's rule) [1]. Thus heptalene (Scheme 1), the polycyclic hydrocarbon composed of two fused cycloheptatriene rings, despite the alternant conjugation, is an unstable, with a non-planar helicity skeleton which also does not satisfy Huckel's or Clar's rule. From the last point of view, pentalene can also be excluded because it has only $4 \mathrm{n} \pi$ electrons. Both compounds are rapidly destroyed even at very low temperatures $\left(-78^{\circ} \mathrm{C}\right.$ to $\left.-100^{\circ} \mathrm{C}\right)[2,3]$. At the other extreme is found the well-known aromatic planar naphthalene, with alternant conjugation and following Clar's rule.

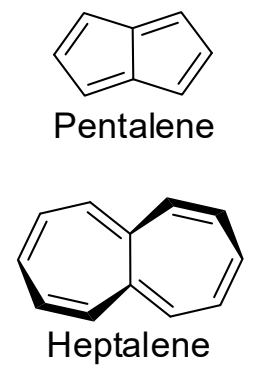

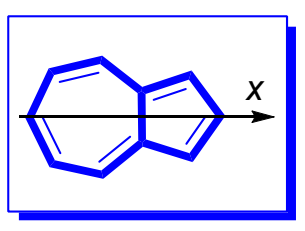

Azulene

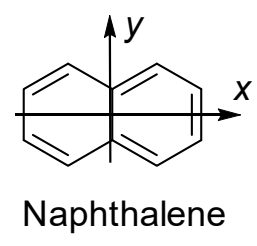

Naphthalene
Scheme 1. Several bicyclic systems with conjugated $\pi$ electrons.

Azulene is naphthalene's isomer, built from a fusion of cyclopentadiene and cycloheptatriene rings. Although this planar compound obeys Huckel's rule, it possesses a non-alternant aromatic structure and at first glance it lacks aromatic sextet [4,5]. However when one electron is transferred from the 7-atom ring to the 5-atom ring, the azulene can be regarded as the fusion of a $6 \pi$-electron cyclopentadienyl anion and a $6 \pi$-electron 
tropylium cation (Scheme 2). The compound polarity is reflected in the presence of the dipole moment (1.08 D).

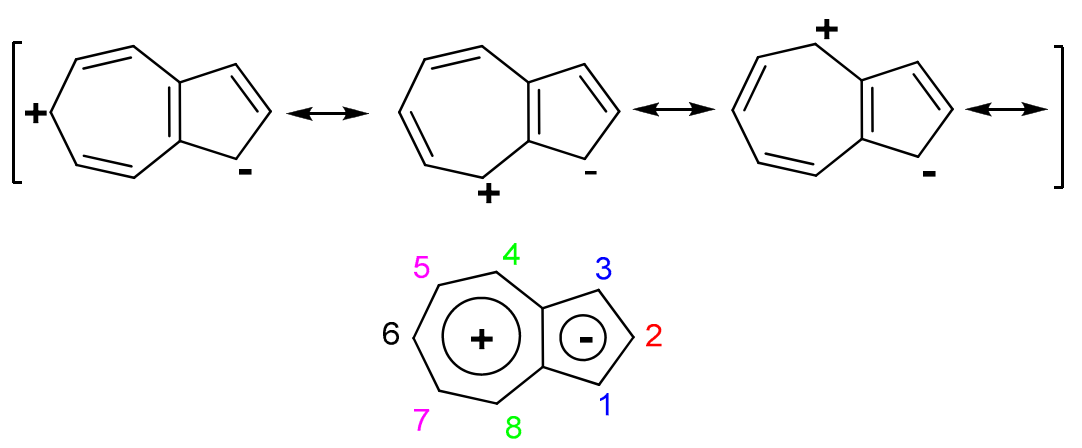

Scheme 2. Azulene: resonance structures and orbital molecular.

Reactivity studies confirm also that the seven-membered ring is electrophilic and the five-membered ring is nucleophilic. The electron transfer can be made to a positively charged substituent (Scheme 3). In this case, the tropylium ion generation provides good stability to the formed cation and, implicitly, an activation of the electrophilic reactions (Scheme 3). While the azulene molecule is symmetrical only with respect to the $x$-axis, naphthalene is supplementary symmetrical with respect to the $y$-axis (Scheme 1). For this reason, azulene has three pairs of identical positions $(1,3 ; 4,8 ; 3,7)$ and two distinct positions ( 2 and 6 ) while naphthalene twice has four identical positions ( $\alpha$ and $\beta$ ). These positions have different charges, therefore different reactivity. In comparison with other benzenoid hydrocarbons, the difference between the small highest occupied molecular orbital-lowest unoccupied molecular orbital (HOMO-LUMO) ensures its remarkable chemical, electronic or optical behavior [6].<smiles>[R12]c1cccc2c([O-])ccc-2c1</smiles>

$\mathrm{R}_{\mathrm{az}}$ : substituent(s) at azulene $\mathrm{Q}$ : moiety with positive charge

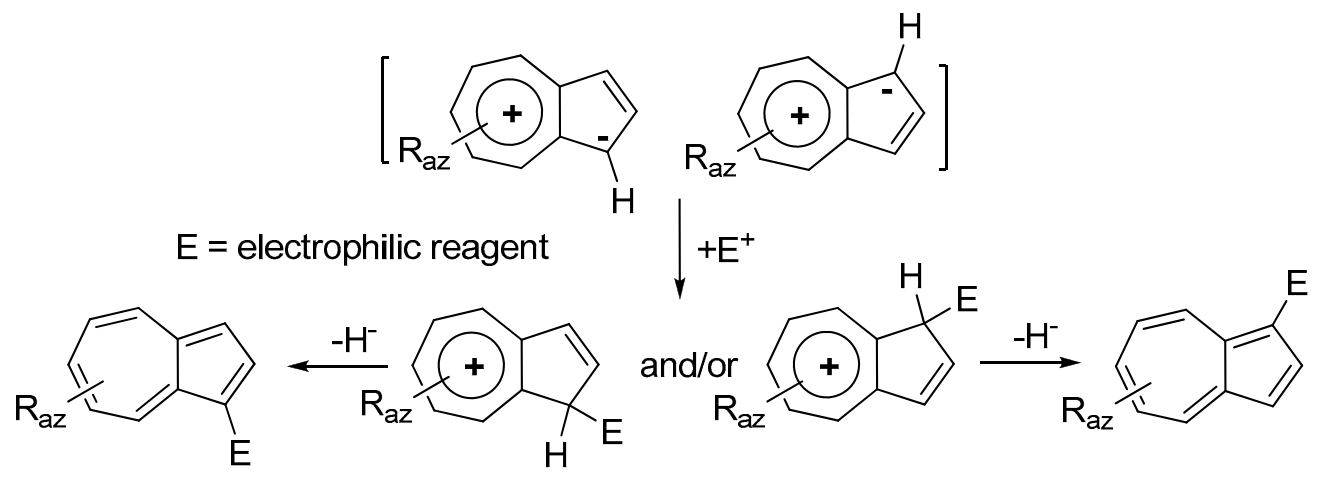

Scheme 3. Tropylium system involvement as stabilizer.

As a result of these considerations, this short survey is devoted to the behavior of azulene-1-yl moiety as electron reservoir which influences several systems that include it. Special attention was given to the synthesis of such interesting systems. The examination of these topics is not exhaustive and is addressed especially to those who want to obtain information on an aspect of the complex chemistry of azulene. 


\section{Triaryl-methylium Ion with at Least One Azulen-1-yl Moiety}

One of the best known and most commonly studied effects of azulen-1-yl moiety as electron donor is the high stability that it gives to the attached cation generating the highly stable pseudo-base, (azulen-1-yl)methylium ions (Scheme 4), whereas from the $\mathrm{pK}_{\mathrm{R}}{ }^{+}=-6.4$ found for triphenylmethylium ion, the value of this parameter increases to 11.5 for the tri(azulen-1-yl)methylium ion [7]. As can be seen in Scheme 4 the $\mathrm{pK}_{\mathrm{R}}{ }^{+}$value increases dramatically with the number of azulen-1-yl at the cation center. Thus, the presence of two such moieties ensures a high cation stability reflected by the $\mathrm{pK}_{\mathrm{R}}{ }^{+}=7.3$. Introduction of aryl, heteroaryl, but especially of azulen-1-yl as the third substituent raises this parameter over 10. Therefore, obtaining these last chemical species and the study of their behavior have been and continue to be a concern for several research groups.

$\begin{array}{rrr} & \mathrm{R}^{1}, \mathrm{R}^{2}, \mathrm{R}^{3} & \mathrm{pK}_{\mathrm{R}}{ }^{+} \\ \mathrm{R}^{1} & \mathrm{Ph}, \mathrm{Ph}, \mathrm{Ph} & -6.4 \\ \mathrm{C}^{+}-\mathrm{R}^{2} & \underline{\boldsymbol{A z}}, \mathrm{Az}, \mathrm{Az} & 11.3 \\ \mathrm{R}^{3} & \underline{\mathbf{A z}}, \mathrm{Az}, \mathrm{Ph} & 10.5 \\ & \underline{\mathbf{A z}}, \mathrm{Ph}, \mathrm{Ph} & 3.0 \\ & \underline{\underline{A z}}, \mathrm{Az}, \mathrm{H} & 7.3\end{array}$

$\underline{\mathrm{Az}}=$ azulen-1-yl

Scheme 4. $\mathrm{pK}_{\mathrm{R}}{ }^{+}$values for some methylium ions.

Most synthesis of (azulen-1-yl)methylium ions are based on the reaction of nucleophilic azulene with electrophiles obtained in different ways, some of which will be presented in the following.

The carbocation resulting from the protonation of carbonyl double bond (compound 1 in Scheme 5) or derived from carbinlos (compound 2) reacts with azulene and, depending on the conditions used, a series of reactions stop at the carbenium salts (step a in Scheme 5) while others directly give neutral product 3 (step $a+b$ or $b^{\prime}$ ). From the compounds 3 , the corresponding salts 4 are synthetized by hydride extraction with DDQ (2,3-dichloro-5,6dicyano- $p$-benzoquinone) in the presence of $\mathrm{HPF}_{6}$ or, less often, using $\mathrm{Ph}_{3} \mathrm{C}^{+} \mathrm{PF}_{6}{ }^{-}$(step c or $\left.\mathrm{c}^{\prime}\right)$. When azulenes unsubstituted in positions 1 and 3 were condensed with carbonylic compounds, both these positions can be occupied and oligomers may be also present in the reaction mixture, or are the only products.

Azulenes were reacted with mono or diphenyl carbinols with the aim to obtain (azulen-1-yl)methane with one or two unsubstituted or substituted phenyl moieties at the central carbon atom (Scheme 5) [8-10]. Neither the generation of primary carbocation nor the intermediate azulenium ion were highlighted. The reactions occurred with good yields in acetic acid with the addition of a few drops of $\mathrm{H}_{2} \mathrm{SO}_{4}$ and, together with the product substituted in position 1 , the reaction mixture contains a reduced amount of 1,3-disubstituted product.

The reaction of carbonylic derivatives with azulenes represents and continues to be a constant focus of interest for researchers. Both the scientific importance and the practical applications of the obtained compounds contribute to this. Several examples will illustrate the synthesis pathways, the nature of the resulting products and some of their properties.

The condensation of azulenes with formaldehyde and other aldehydes started in the 1950s-1960s [11]. The early reactions occurred either in ether in the presence of $\mathrm{HCl}$ [11] or with $\mathrm{HClO}_{4}$ in acetic acid or in tetrahydrofuran [12]. The latter reaction conditions were applied to reactions of guaiazulene with aryl or heteroaryl aldehydes with good yields (between $20 \%$ and $97 \%$ ), giving perchlorates of (guaiazulen-3-yl)methylium ion with other substituent(s) in positively charged carbon. In attempts with azulene instead of guaiazulene the yield decreased due to a larger or smaller number of formed oligomers or polymers. The presence of di(azulen-1-yl)methane from the azulene-1-carbaldehyde and azulene via perchlorate intermediate was also reported, however without the product characteriza- 
tion. Here it must be noted that for a long time the absence of elaborate procedures for product characterization (e.g., NMR or MS spectroscopy) has been a serious obstacle to the unequivocal assignment of the structure of some obtained products. This assignment was made mainly on the basis of UV-Vis/IR spectra and elemental analysis. Several reactions of azulene also used benzaldehydes [10] or aliphatic aldehydes and ketones [13]. In 1961 Hafner and al. reacted azulen-1-carbaldehyde and 4,6,8-trimethylazulen-1-carbaldehyde with azulene in the presence of $\mathrm{POCl}_{3}$ followed by treatment with NaI to obtain di(azulen1-yl)methylium iodides [14]. The same authors synthesized tri(azulen-1-yl)methylium chloride ( $87 \%$ yield) after the reaction of azulene with tetra-ethoxy-methane in the presence of $\mathrm{HCl}$ in nitromethane.

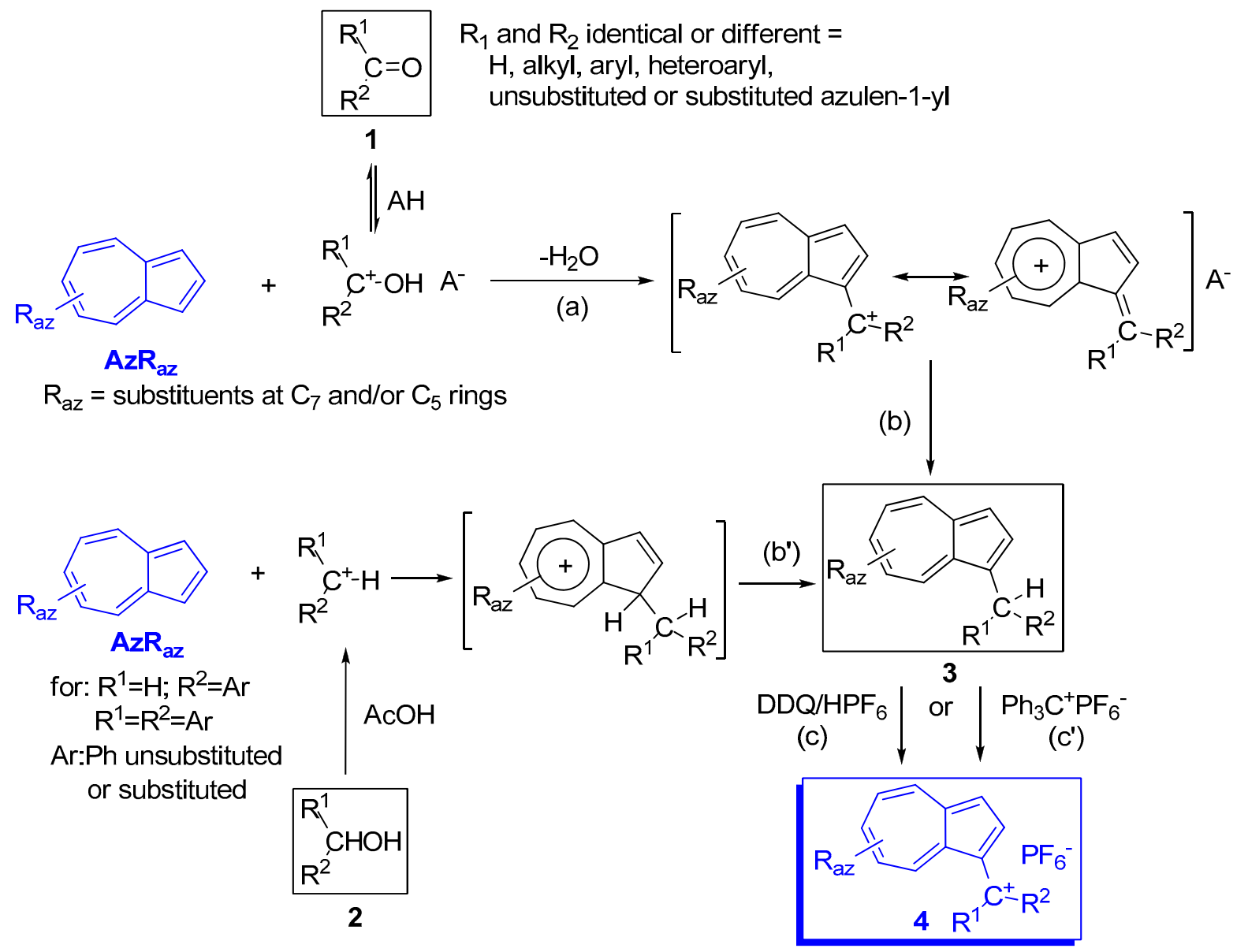

Scheme 5. General route for the synthesis of azulen-1-yl(s) methylium ions.

Systematic research into building and studying the salts of triaryl-methylium ions with one to three azulen-1-yl contribution, and with other aryl or heteroaryl moieties at charged carbon, has been undertaken especially by Asao et al. since $1990[7,15]$. In addition to very high stability achieved by the azulen-1-yl moiety mentioned above [16], another target pursued by the authors was the study of the propeller shaped structure which can be adopted by some triaryl-methylium ions, mainly those containing three azulen-1-yl moieties at the cationic center. The results obtained indicate that favorable conjugation contributes to the transition state of the ring flipping as well as to the ground state. Therefore, these cations show a unique dynamic stereochemical behavior [17-20]. The general route for the synthesis of these salts involves two steps: the condensation of azulene with different aromatic or heteroaromatic aldehydes in acetic acid, followed by hydride removal from the substituted methane. An example of this reaction sequence is given in Scheme 6 for obtaining methylium salts substituted with three azulen-1-yl moieties, 9, or with two azulen-1-yl and phenyl, 10 via neutral intermediates 5 and $\mathbf{7}$. The hydride 
removal with DDQ gave the expected result, whereas attempts using $\mathrm{Ph}_{3} \mathrm{P}^{+}$depended on a neutral compound. Hydride elimination with the help of $\mathrm{Ph}_{3} \mathrm{P}^{+}$proceedes normally starting from compound 7 but using compound 5 one azulen-1-yl group is substituted by phenyl, leading to product $\mathbf{1 1}$ (azulenes $\mathbf{1 2}$ and $\mathbf{1 3}$ were formed as by-products) [21]. Working with azulene without substituents in position 1 and 3 , the azulene can act as a spacer and compounds with the structures $\mathbf{6}$ and $\mathbf{8}$ were highlighted in low amounts. In this case, as well as when azulene has a substituent that can be replaced electrophilically (e.g., $t$ Bu group) in position 1 and /or 3 , the yield decreases due to the formation of oligomers. Oligomers such as $\mathbf{6 A}$ and $\mathbf{8 A}$ were converted into bis methylium derivatives, $\mathbf{6 B}$ and $\mathbf{8 B b}$, after hydride(s) removal.
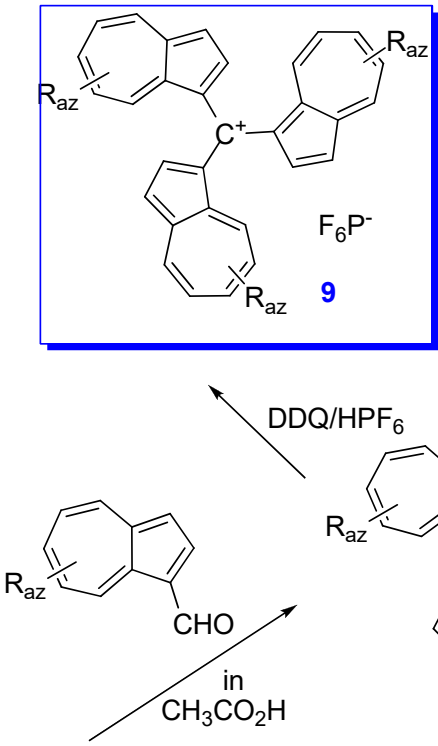

$\mathrm{R}_{\mathrm{az}}$

$\mathrm{AzR}_{\mathrm{az}}$<smiles>CC(C)c1ccc(C=O)cc1</smiles>

$\mathrm{R}_{\mathrm{az}}=$ substituent(s) at $\mathrm{C}_{3}$ and/or $\mathrm{C}_{7}$ ring $\mathrm{R}_{\mathrm{ph}}=$ substituent at phenyl

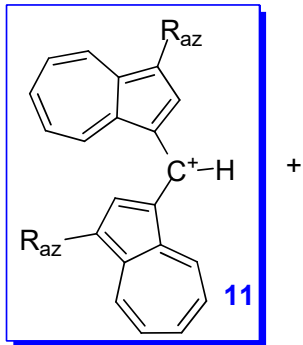

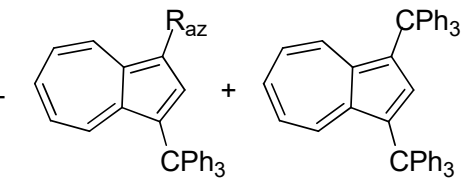

12

13

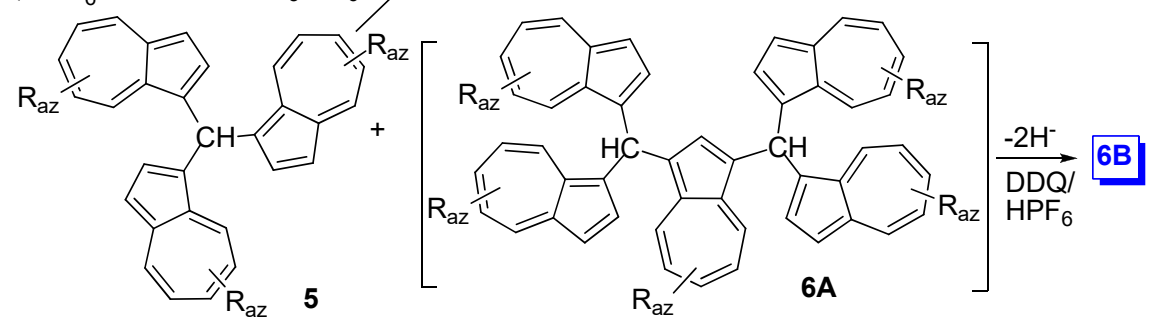

only when $\mathrm{R}_{\mathrm{az}}=\mathrm{H}$; low amount

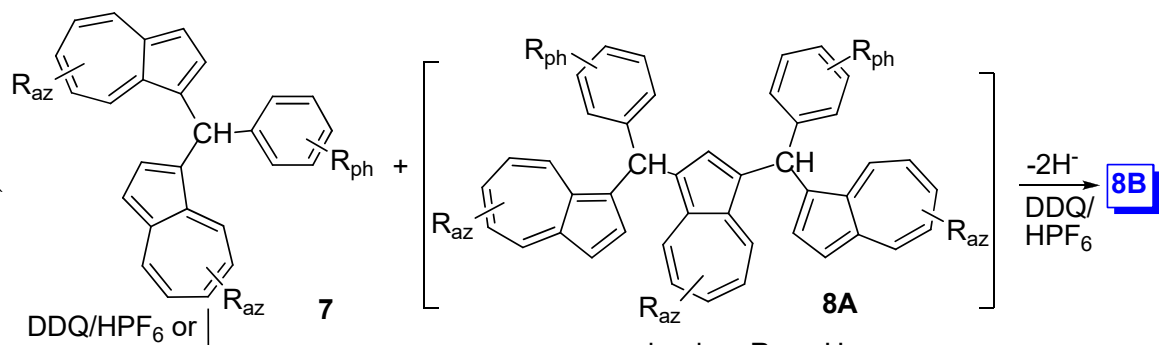

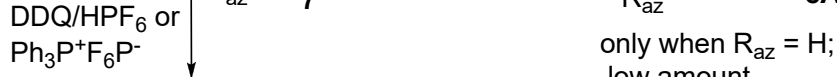<smiles>Fc1ccc([C](c2ccc3ccccc3c2)c2cccc3ccccc23)c(F)c1</smiles>

low amount

Scheme 6. Synthesis of methylium salts incorporated in azulen-1-yl moieties.

Another objective pursued was the obtaining of as varied information as possible when both azulene and phenyl moieties included in the methylium ion were substituted. Nevertheless, because of the large volume of the reported data, only some of the most illustrative compounds, 9, 10 and 14, will be briefly discussed below (Scheme 7). 

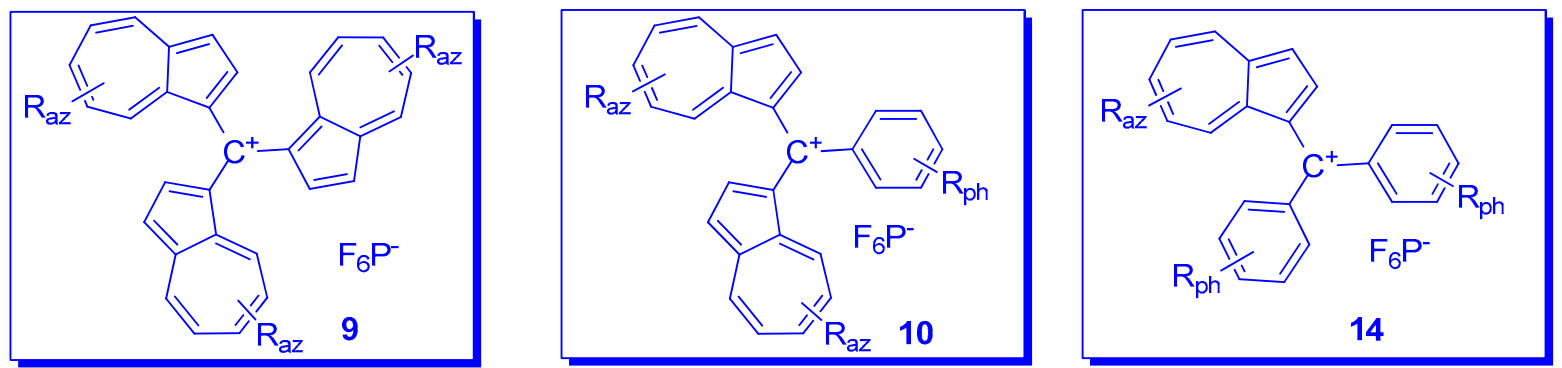

$\mathrm{R}_{\mathrm{ph}}=\mathrm{H} ; \quad \mathrm{R}_{\mathrm{az}}=\mathrm{H}, 2-\mathrm{Me}, 3-\mathrm{Me}, 3-\mathrm{CO}_{2} \mathrm{Me}$, 3-tBu, 6-tBu, 3,6-di $t \mathrm{Bu}$

$\mathrm{R}_{\mathrm{ph}}=4-\mathrm{OMe}$ or 4-NMe $\mathrm{N}_{2} ; \quad \mathrm{R}_{\mathrm{az}}=\mathrm{H}, 3,6$-di $t \mathrm{Bu}, 6-\mathrm{OMe}, 6-\mathrm{NMe}_{2}$

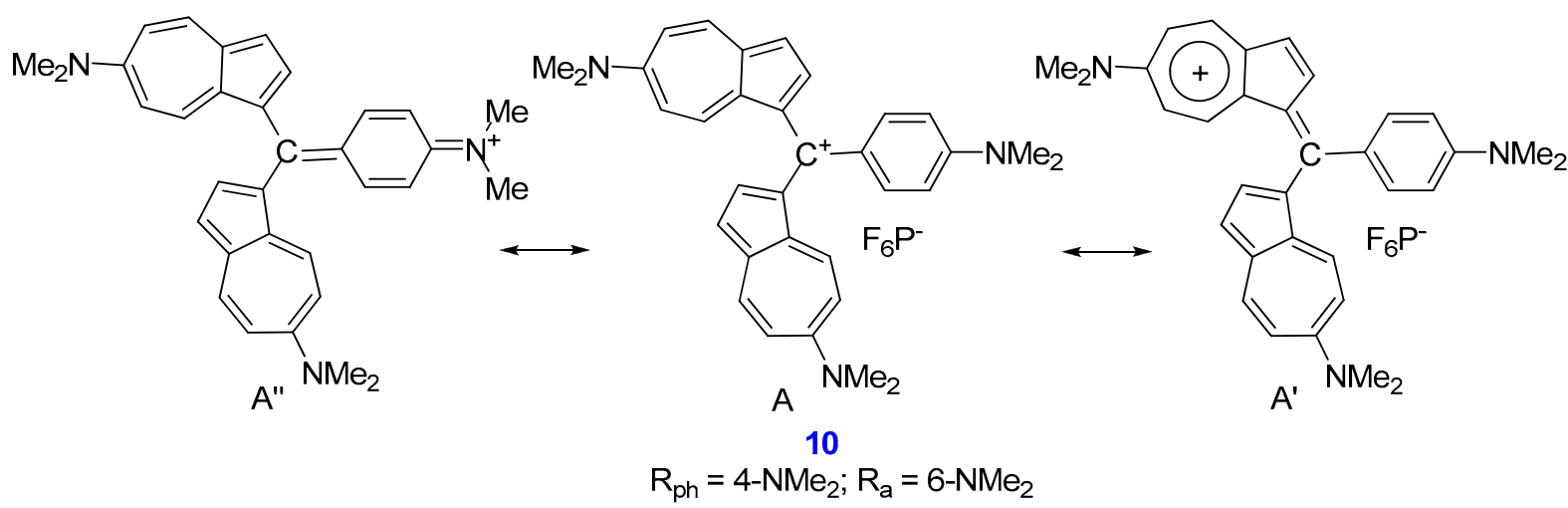

Scheme 7. Methylium ions with substituted azulene and/or phenyl moieties.

As mentioned above and as a result of the values for $\mathrm{pK}_{\mathrm{R}}+$ collected in Table 1,the increased number of azulen-1-yl moieties at the methylium center increases the stability of the system and the azulene substituents can decisively influence this parameter. Thus, the $\mathrm{pK}_{\mathrm{R}}+$ for $9\left(R_{a z}=3-M e\right)$ (Scheme 7) is similar to the compound without substituent $9\left(R_{a z}=H\right)$. However, the large $t \mathrm{Bu}$ groups in position 3,9 $\left(\mathrm{R}_{\mathrm{az}}=3-t \mathrm{Bu}\right)$, increases substantially the $\mathrm{pK}_{\mathrm{R}}+$ and, for the presence of two such groups in positions 3 and 6, $9\left(\mathrm{R}_{\mathrm{az}}=3,6-\mathrm{di} t \mathrm{Bu}\right)$, the value exceeds that of the unsubstituted compound by three units. It has been suggested that this increase can be attributed to the steric effect and less to hyperconjugation [16]. The contribution of the donor substituents such as OMe [22,23] or $\mathrm{NMe}_{2}[24,25]$ to phenyl and /or azulene is more important. As shown in Scheme 7, for cation $\mathbf{1 0}\left(\mathrm{R}_{\mathrm{ph}}=\mathrm{R}_{\mathrm{az}}=\mathrm{Me}_{2} \mathrm{~N}\right)$ the charge is distributed between the resonance structures $\mathrm{A}, \mathrm{A}^{\prime}$ and $\mathrm{A}^{\prime \prime}$, namely methylium, tropylium, and ammonium ions. Although the contribution of the ammonium group is remarkable, it is smaller than that exerted by the tropylium. Thus, the difference between the $\mathrm{pK}_{\mathrm{R}}+$ values of the tri(4-dimethylaminophenyl)methylium ion [26] and that for the corresponding tri(azulen-1-yl)methylium ion, $9\left(\mathrm{R}_{\mathrm{az}}=6-\mathrm{Me}_{2} \mathrm{~N}\right)$, namely 9.36 and 24.3 , can be a suggestive example. Therefore, it can be concluded that the extreme stability of the last methylium ion is due to the dipolar structure of the azulene rings, in addition to the contribution of the mesomeric effect of the di-methyl-amino groups.

The influence of azulen-1-yl moieties on the positive charge at the cationic carbon is also well reflected by the ${ }^{13} \mathrm{C}-\mathrm{NMR}$ spectra in series of compounds $\mathbf{9 , 1 0}$ and $\mathbf{1 4}$. The up-field chemical shifts for $\mathrm{C}^{+}$belonging to these compounds observed at 151.82-161.38, 161.11-169.83 and 168.58-177.68 ppm, respectively, indicates a decrease in charge at $C^{+}$ in the series and an enhanced thermodynamic stability. The chemical shift of $\mathrm{C}^{+}$in 9 $\left(\mathrm{R}_{\mathrm{az}}=3,6\right.$-di $\left.t \mathrm{Bu}\right)$ at $151.82 \mathrm{ppm}$ (in DMSO- $\mathrm{d}_{6}$ ) is slightly up-field compared with those in $9\left(\mathrm{R}_{\mathrm{az}}=\mathrm{H}\right.$ and $\left.\mathrm{Me}\right)$ at 157.40 and $154.17 \mathrm{ppm}$. Considerable up-fields occur for $\mathbf{1 0}$ $\left(\mathrm{R}_{\mathrm{az}}=\mathrm{H}\right.$ and $\left.\mathrm{Me}\right)$ at 165.54 and $161.58 \mathrm{ppm}$ in $\left.\mathrm{CDC1}_{3}\right)[7,15,16]$. It should be noted that, despite the impressive stability of compounds $\mathbf{9 , 1 0}$ and $\mathbf{1 4}$ with $R_{\mathrm{ph}}=\mathrm{R}_{\mathrm{az}}=\mathrm{NMe}_{2}$ the 
chemical shifts for $\mathrm{C}^{+}$for these cations $(156.44,162.08$, and $169.98 \mathrm{ppm}$, respectively) are almost comparable with those with $\mathrm{R}_{\mathrm{ph}}=\mathrm{R}_{\mathrm{az}}=\mathrm{H}$ [25].

Table 1. $\mathrm{pK}_{\mathrm{R}}{ }^{+}$for the compounds 9,10 and 14 .

\begin{tabular}{ccccc}
\hline $\mathbf{R}_{\mathbf{a z}}$ & $\mathbf{R}_{\mathbf{p h}}$ for $\mathbf{1 0}$ and $\mathbf{1 4}$ & $\mathbf{9}$ & $\mathbf{p K}_{\mathbf{R}}{ }^{+}$ & $\mathbf{1 4}$ \\
\hline $\mathrm{H}$ & $\mathrm{H}$ & 11.3 & 10.5 & 3.0 \\
$3-\mathrm{Me}$ & $\mathrm{H}$ & 11.4 & 10.8 & 3.7 \\
$3-t \mathrm{Bu}$ & - & 13.2 & - & - \\
$3,6-\mathrm{di} t \mathrm{Bu}$ & $\mathrm{H}$ & 14.3 & 12.4 & 4.6 \\
$6-\mathrm{OMe}$ & - & $>14.0$ & - & - \\
$\mathrm{H}$ & $4-\mathrm{OMe}$ & - & 11.7 & - \\
$6-\mathrm{OMe}$ & $4-\mathrm{OMe}$ & - & 714.0 & - \\
$3,6-\mathrm{di} t \mathrm{Bu}$ & $4-\mathrm{OMe}$ & - & 13.4 & - \\
$\mathrm{H}$ & $4-\mathrm{Me}_{2} \mathrm{~N}$ & - & 13.2 & - \\
$3,6-\mathrm{di} t \mathrm{Bu}$ & $4-\mathrm{Me}_{2} \mathrm{~N}$ & - & - & 12.6 \\
$\mathrm{H}$ & $4-\mathrm{Me}_{2} \mathrm{~N}$ & - & - & - \\
$3,6-\mathrm{di} t \mathrm{Bu}$ & $4-\mathrm{Me}_{2} \mathrm{~N}$ & - & - & - \\
$6-\mathrm{Me}{ }_{2} \mathrm{~N}$ & - & 24.3 & 21.5 & 13.3 \\
$6-\mathrm{Me}{ }_{2} \mathrm{~N}$ & $4-\mathrm{Me}_{2} \mathrm{~N}$ & - & - & - \\
$6-\mathrm{Me}{ }_{2} \mathrm{~N}$ & $4-\mathrm{Me}_{2} \mathrm{~N}$ & - & 11.2 & - \\
$3-\mathrm{Me}(\mathbf{1 8 a})$ & $2-$ thienyl & - & 11.8 & - \\
$3-t \mathrm{Bu}(\mathbf{1 8 a})$ & $2-$ thienyl & - & 11.4 & - \\
$3-\mathrm{Me}(\mathbf{1 8 b})$ & 3-thienyl & - & 12.4 & \\
$3-t \mathrm{Bu}(\mathbf{1 8 b})$ & 3-thienyl & - &
\end{tabular}

Several compounds have also been reported in which phenyl has been replaced by another aryl or heteroaryl group. In addition to the partially characterized compounds reported by Kirby and Reid in 1960 [12], more recently phenyl was replaced with 2- and 3 -thienyl as in compounds 15a,b depicted in Scheme 8 [27]. These substituents should have a stabilizing effect and, indeed, the chemical shifts of $C^{+}$for compounds $15 a\left(R_{a z}=3-M e\right)$ and $15 \mathrm{~b}\left(\mathrm{R}_{\mathrm{az}}=3-\mathrm{Me}\right)$ at 151.8 and $153.7 \mathrm{ppm}$, respectively, showed significant up-field shift compared with those for the corresponding benzyl cations $\mathbf{1 0}\left(\mathrm{R}_{\mathrm{az}}=3-\mathrm{Me}, \mathrm{R}_{\mathrm{ph}}=\mathrm{H}\right)$ at $161.1 \mathrm{ppm}$. However, despite their stabilizing effect, as seen in Table 1, the values of $\mathrm{pK}_{\mathrm{R}}+$ belonging to the thienyl compounds are comparable with those of the analogous phenyl moiety.

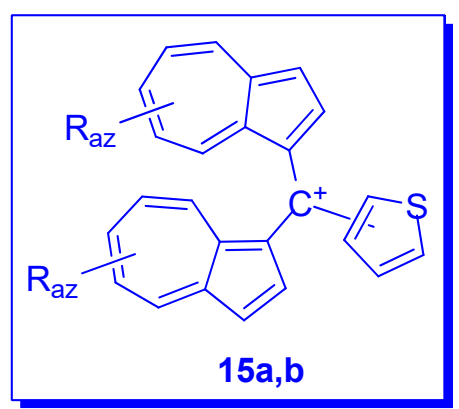

a:2-substituted; b:3-substituted thienyl $\mathrm{R}_{\mathrm{az}}=3-\mathrm{Me}, 3,6$-di $t \mathrm{Bu}$

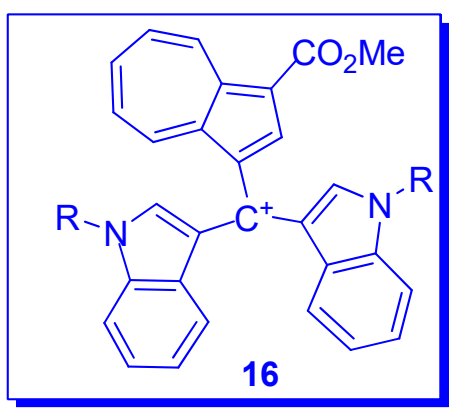

$\mathrm{R}=\mathrm{Me}, \mathrm{Et}$

Scheme 8. Methylium ions substituted with heteroaromatic moiety.

Another type of (azulen-1-yl)methylium ion was obtained by the acid catalyzed condensation of methyl 3-formylazulene-1-carboxylate with indoles (Scheme 8) [28]. The resulting triarylmethanes were oxidized with DDQ to the corresponding azulene-1-yldi(indol-3-yl)methylium hexafluorophosphates, 16, with high $\mathrm{pK}_{\mathrm{R}}{ }^{+}$values (12-14 units), comparable to those of the triazulen-1-ylmethylium ion. Unprotected indoles do not give 
clean condensation due to their capacity to deformylate the azulenic system. Therefore, indole must be substituted at the nitrogen atom.

In addition to the bis methylium ions with azulene as spacer, $\mathbf{6 B}$ and $\mathbf{8 B}$ (Scheme 6), other spacers as 1,4- or 1,3-phenylene, $\mathbf{1 7}$ or $\mathbf{1 8}$ [29], as well as 2,5-thiophenediyl, $\mathbf{1 9}$ and 2,5-thienothiophenediyl, 20 [27] were synthesized and studied (Scheme 9). A special case is represented by the spectacular tri-methylium ion $\mathbf{2 1}$ where the positive charged carbons are placed in 1,3,5 positions of phenyl as spacer [30].
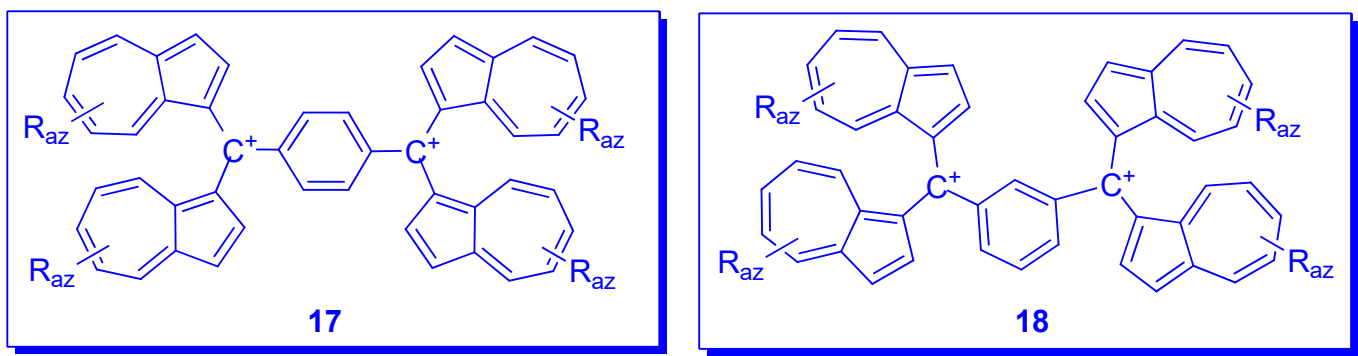

$\mathrm{R}_{\mathrm{az}}=3-\mathrm{Me}, 3,6-\mathrm{di} t \mathrm{Bu}$
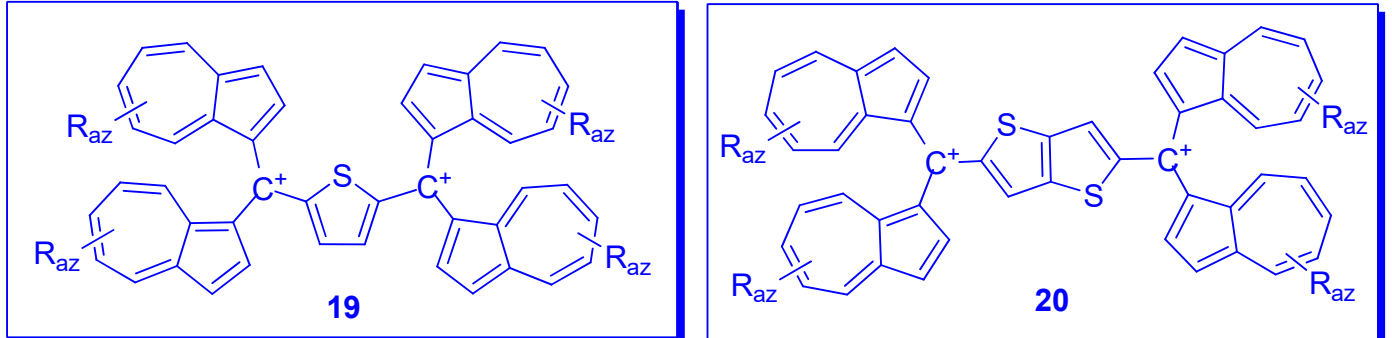

$\mathrm{R}_{\mathrm{az}}=3-\mathrm{Me}, 3,6-\mathrm{di} t \mathrm{Bu}$

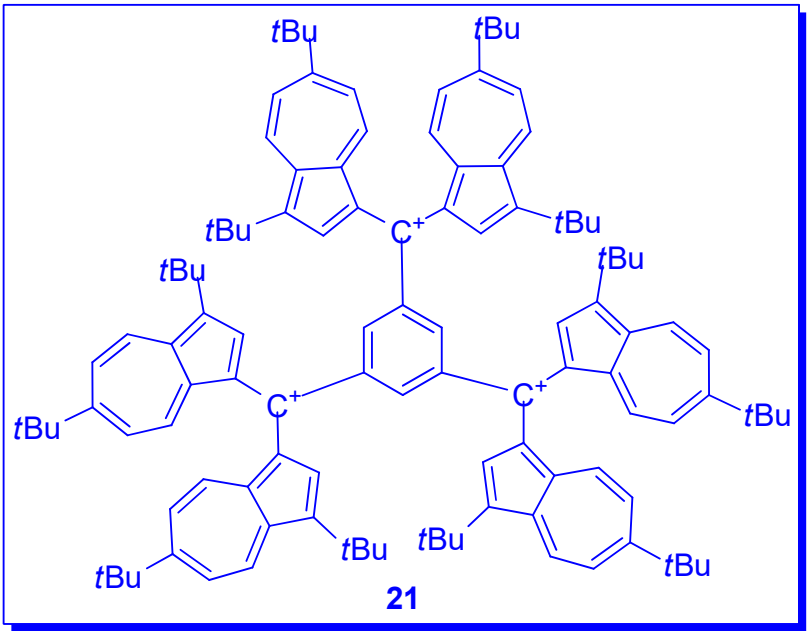

Scheme 9. Methylium ions substituted at spacers.

The special properties such as conductivity and ferro-magnetism of several multistage redox systems [31] contributed to the desire to build such stable cationic multistage redox systems by connecting redox systems with an extremely stable carbocation and examining how the redox properties would be changed. In this direction the research must be mentioned which took into account redox properties of the ferrocene and extreme stabilities of the di(1-azulenyl)methylium units [32]. In this aim (Scheme 10) di(azulen-1-yl)ferrocenyl-methylium hexafluorophosphate, $22\left(\mathrm{R}^{1}=\mathrm{R}^{2}=\mathrm{H}\right.$ or $\left.t \mathrm{Bu}\right)$ and $\mathbf{2 2}\left(\mathrm{R}^{1}=\mathrm{Me} ; \mathrm{R}^{2}=\mathrm{H}\right)$ as well as the di-cation $\mathbf{2 3}$ were synthesized. As expected, due to the stabilizing effect of the 
electron donor ferrocene moiety, the $\mathrm{pKR}+$ of $22\left(\mathrm{R}^{1}=\mathrm{R}^{2}=\mathrm{H}\right)$ slightly increased, compared to those of the phenyl analogues, although the chemical shift for ${ }^{13} \mathrm{C}$ of the central cationic carbons of salts 22 are almost comparable with those in the phenyl analogues.

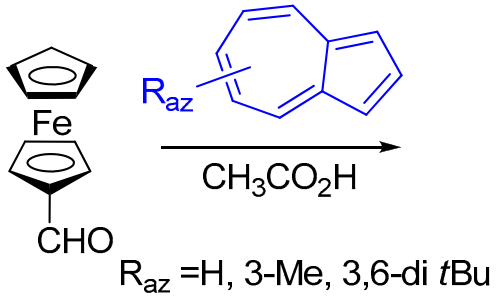

values for $\mathrm{pK}_{\mathrm{R}^{+}}$

22( $\left(\mathrm{R}_{\mathrm{az}}=\mathrm{H}\right)$

22( $\left.\mathrm{R}_{\mathrm{az}}=3-\mathrm{Me}\right)$

22( $R_{a z}=3,6$-di $\left.t \mathrm{Bu}\right) 12.5 \pm 0.4$

$12.2 \pm 0.3$

$12.2 \pm 0.4$

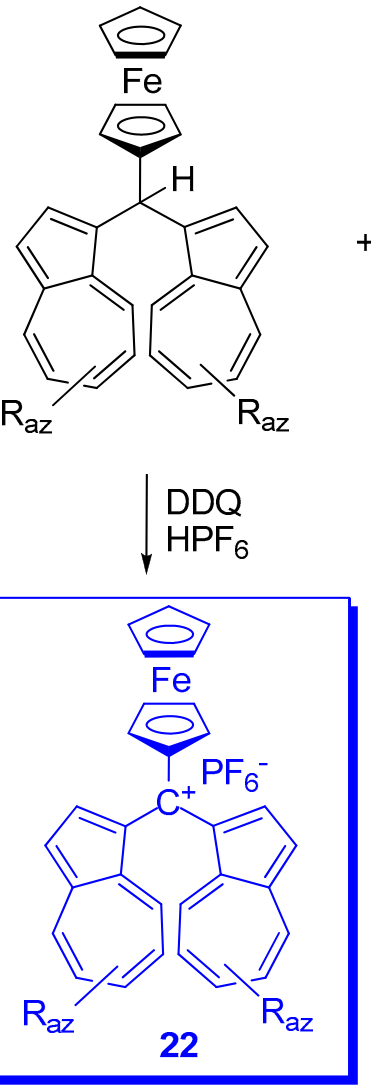

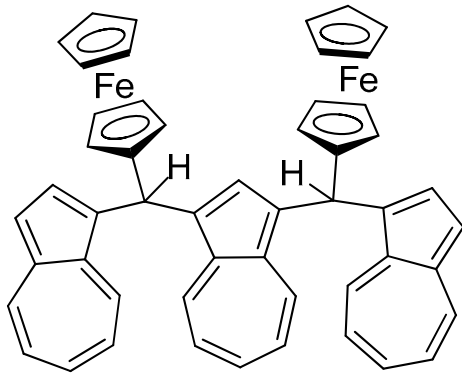

only when $\mathrm{R}_{\mathrm{az}}=\mathrm{H}$

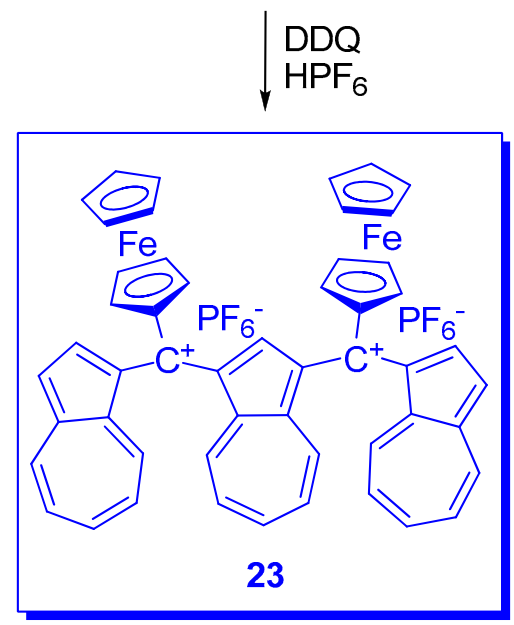

Scheme 10. Di(azulen-1-yl)ferro-cenyl-methylium hexafluorophosphate.

\section{Charged Hetero-aryls Stabilized by Azulen-1-yl Moieties}

Two reviews on the synthesis of azulenes substituted with heterocyclic moieties were recently published $[33,34]$. Consequently, in this chapter only the syntheses of compounds with charged heterocycles will be briefly examines and attention will be paid to the consequences of their substitution with azulen-1-yl moieties.

Pyranylium salts, which present interesting properties that make them useful for various technical purposes, are stabilized by substitution with electron donating (or releasing) groups. One of the substituents tested for this purpose was azulen-1-yl moiety situated in 2- or 4-position towards the oxonium center of pyranylium. The reported azulenyl-pyranylium system reported earlier described syntheses for 4-(azulen-1-yl) 2,6diphenyl-pyranylium salts $[35,36]$. Chloro-pyranylium salt or even pyranylium salt were starting compounds. The obtained products were characterized by melting points, elemental analysis and sometimes infrared spectra. In the desire to obtain a large and varied number of pyranylium salts with azulene moieties as substitute and to start from these salts in the synthesis of pyridines, pyridinium salts or bis azulene, Razus et al. varied both the hetero-cycle and azulene substituents [37]. The reaction route and the obtained 4-(azulen-1-yl)pyranylium salts are described in Scheme 11. Thus, 4H-pyran-4-ones 1 was reacted with $\mathrm{PCl}_{5}$ or $\mathrm{POCl}_{3}$ and perchloric acid. When $\mathrm{R}_{\mathrm{az}}=\mathrm{Ph}$ the intermediate 2 was separated and characterized whereas for $R_{a z}=$ Me the reaction was continued without separation of unsTable 2. The redoubtable nucleophilicity of azulene chlorine leads to substitution yields ranging from satisfactory to very good. Scheme 11 shows that the obtained pyranylium salts have various substituents at azulene and the 2 and 6 positions of 
the heterocycle are substituted with phenyl, methyl, thiophen-2-yl or furan-2-yl. Position 3 in the heterocycle was also occasionally substituted.<smiles>[R2]c1cc(=O)c([R])c([R])o1</smiles>

1<smiles>[R]c1cc(Cl)c([R])[o+]c1[O-]</smiles>

2

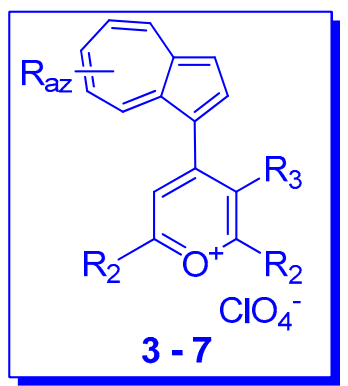

Yields for reactions $2 \longrightarrow 3-7$ : $50-90 \%$

3: $\mathrm{R}_{3}=\mathrm{H} ; \mathrm{R}_{2}=\mathrm{Ph}$ $\mathrm{R}_{\mathrm{az}}=\mathrm{H}, 3$-and 6-Me, 3-tBu, 4,8-Me $\mathrm{M}_{2}$ 4,6,8- $\mathrm{Me}_{3}, 2-t \mathrm{Bu}, 6-\mathrm{Me}, 5-\mathrm{iPr}, 3,8-\mathrm{Me}_{2}$ $\mathrm{NHAc}, \mathrm{OMe}, \mathrm{OOCPh}, \mathrm{COOMe}, \mathrm{PhN}=\mathrm{N}, \mathrm{CHO}, \mathrm{NO}$

4: $\mathrm{R}_{3}=\mathrm{Me}, \mathrm{Ph}, \mathrm{Br} ; \mathrm{R}_{2}=\mathrm{Ph}$

$R_{\mathrm{az}}=\mathrm{H}, 4,6,8-\mathrm{Me}_{3}, 2-t \mathrm{Bu}, 6-\mathrm{Me}, 5-i \mathrm{Pr}, 3,8-\mathrm{Me}_{2}$

5: $\mathrm{R}_{3}=\mathrm{H} ; \mathrm{R}_{2}=\mathrm{Me}$

$\mathrm{R}_{\mathrm{az}}=\mathrm{H}, 4,6,8-\mathrm{Me}_{3}$, 2-tBu,6-Me, 5-iPr,3,8-Me

6: $\mathrm{R}_{3}=\mathrm{H} ; \mathrm{R}_{2}=$ thiophen-2-yl

$\mathrm{R}_{\mathrm{az}}=\mathrm{H}, 4,6,8-\mathrm{Me}_{3}, 5-\mathrm{iPr}, 3,8-\mathrm{Me}_{2}$

7: $\mathrm{R}_{3}=\mathrm{H} ; \mathrm{R}_{2}=$ furan-2-yl

$\mathrm{R}_{\mathrm{az}}=\mathrm{H}, 4,6,8-\mathrm{Me}_{3}, 5-\mathrm{iPr}, 3,8-\mathrm{Me}_{2}$

Scheme 11. Synthesis of 4-(azulen-1-yl)pyranylium salts.

Table 2. ${ }^{1} \mathrm{H}-\mathrm{NMR}$ spectra of substituted azulenic compounds (chemical shifts in ppm).

\begin{tabular}{ccccccc}
\hline${ }^{\mathbf{1}} \mathbf{H}$ & Azulene & $\begin{array}{c}\text { 1-Phenyl- } \\
\text { azulene }\end{array}$ & $\begin{array}{c}\text { 4-(Azulen-1-yl)- } \\
\text { 2,6-diphenylpyridine }\end{array}$ & Salt 3 $^{\mathbf{a}}$ & Salt 5 $^{\mathbf{b}}$ & Salt 10 $^{\mathbf{c}}$ \\
\hline $3^{\prime}{ }^{\prime} 5^{\prime} \mathrm{H}$ & - & - & 7.95 & 8.83 & 8.06 & 8.32 \\
2 & 7.81 & 8.02 & 8.18 & 8.92 & 8.45 & 7.18 \\
3 & 7.30 & 7.43 & 7.53 & 7.77 & 7.51 & 7.35 \\
4 & 8.23 & 8.34 & 8.44 & 8.89 & 8.65 & 7.47 \\
5 & 7.05 & 7.14 & 7.28 & 8.03 & 8.07 & 7.72 \\
6 & 7.45 & 7.58 & 7.45 & 8.14 & 7.80 & 7.29 \\
7 & 7.05 & 7.14 & 7.29 & 9.57 & 9.12 & 8.71 \\
8 & 8.23 & 8.55 & 8.71 & & \\
\hline
\end{tabular}

${ }^{\mathrm{a}} \mathrm{R}_{3}=\mathrm{R}_{\mathrm{az}}=\mathrm{H} ; \mathrm{R}_{2}=\mathrm{Ph} .{ }^{\mathrm{b}} \mathrm{R}_{3}=\mathrm{R}_{\mathrm{az}}=\mathrm{H} ; \mathrm{R}_{2}=\mathrm{Me} .{ }^{\mathrm{c}} \mathrm{R}_{\mathrm{az}}=\mathrm{H} ; \mathrm{R}_{2}=\mathrm{Ph} ; \mathrm{R}_{\mathrm{py}}=n \mathrm{Bu}$.

The beneficial effect on the pyranylium ring salt stability can also be exerted by the azulen-1-yl moiety placed in position 2 of the ring as in products 8,9 . The reaction started from $2 \mathrm{H}$-pyran-2-one and occurred as shown in Scheme 12 with good yields when $\mathrm{R}=\mathrm{Ph}$ (36-45\%) and only with $17 \%$ for $\mathrm{R}=\mathrm{Me}[37,38]$.

The pyranylium salts were then used as valuable synthons for obtaining a series of pyridines and pyridinium salts [34]. The general pathway for the synthesis of pyridinium salts in two steps [39] was applied to the generation of salts substituted with azulen-1yl moieties (Scheme 13) $[38,40,41]$. In the first step the pyranylium ring is opened by amine in the presence of triethylamine followed by the ring closure of the intermediate enamine. Good or even quantitative yields were reported for products 10, 10' and 11, 12 and the generation of pyridinium salts is not influenced by the amine except when $t \mathrm{BuNH}_{2}$ was used, which lowers the yield. When started from 2,6-dimethylpyranilium 
salts alongside the pyrylium salts 13, traces of anilines 14 were present in almost all reactions with amines; however, using $i \mathrm{PrNH}_{2}$ the amount of aniline reaches a $5-25 \%$ yield. The route for generation of compound $\mathbf{1 4}$ is described in Scheme 13.<smiles>[R]c1cc([R])oc(=O)c1</smiles><smiles>[R]c1cc([R])[o+]c(-c2ccc3ccccc3c2)c1</smiles>

8: $\mathrm{R}=\mathrm{Ph} ; \mathrm{R}_{\mathrm{az}}=\mathrm{H}, 4,6,8-\mathrm{Me}_{3}, 5-i \mathrm{Pr}, 3,8-\mathrm{Me}_{2}$

9: $R=M e ; R_{a z}=H, 4,6,8-M_{3}, 2-t B u, 6-M e, 5-i P r, 3,8-M_{2}$

Scheme 12. Synthesis of 2-(azulen-1-yl)pyranylium salts.<smiles></smiles>

3-7

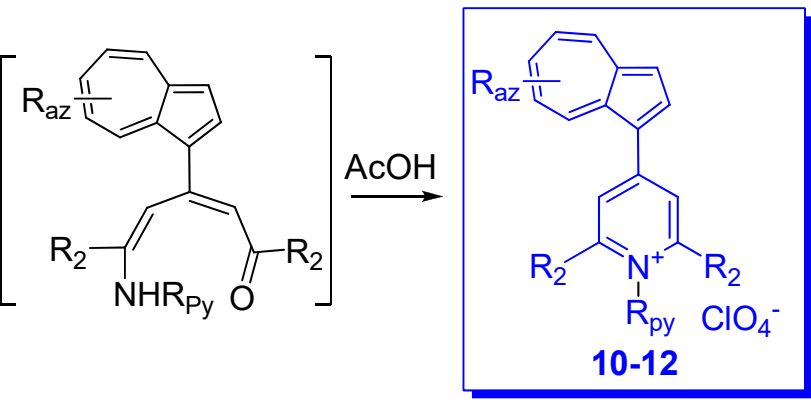

10: $\mathrm{R}_{2}=\mathrm{Ph}$

$\mathrm{R}_{\mathrm{py}}=n \mathrm{Bu}$

$\mathrm{R}_{\mathrm{az}}=\mathrm{H}, 3-\mathrm{Me}, 4,8-\mathrm{Me}_{2}, 4,6,8-\mathrm{Me}_{3}$, 2-tBu,6-Me, 5-iPr,3,8-Me

10': $\mathrm{R}_{2}=\mathrm{Ph}$

$\mathrm{R}_{\mathrm{py}}=\mathrm{H}, \mathrm{Me}, i \mathrm{Pr}, \mathrm{Bn}, t \mathrm{Bu}, \mathrm{Ph}$

$\mathrm{R}_{\mathrm{az}}=\mathrm{H}$
11: $\mathrm{R}_{3}=\mathrm{H} ; \mathrm{R}_{2}=$ thiophen-2-yl

$\mathrm{R}_{\mathrm{az}}=\mathrm{H}, 4,6,8-\mathrm{Me}_{3}, 5-\mathrm{PPr}, 3,8-\mathrm{Me}_{2}$

$\mathrm{R}_{\mathrm{py}}=n \mathrm{Bu}$

12: $\mathrm{R}_{3}=\mathrm{H} ; \mathrm{R}_{2}=$ furan-2-yl

$\mathrm{R}_{\mathrm{az}}=\mathrm{H}, 4,6,8-\mathrm{Me}_{3}, 5-i \mathrm{Pr}, 3,8-\mathrm{Me}_{2}$

$\mathrm{R}_{\mathrm{py}}=n \mathrm{Bu}$

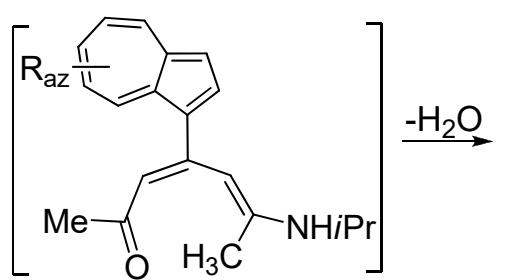

$\mathrm{R}_{\mathrm{az}}=\mathrm{H}, 4,6,8-\mathrm{Me}_{3}, 2-\mathrm{Bu}, 6-\mathrm{Me}$
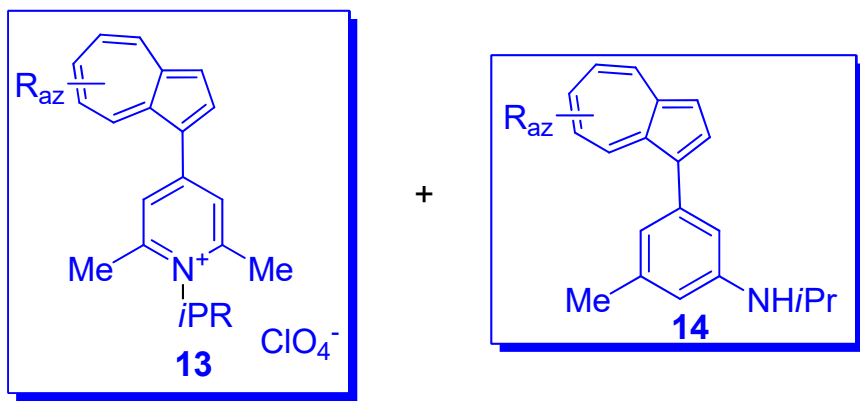

Scheme 13. Synthesis of 4-(azulen-1-yl)pyridinium salts.

Research has also been pursued on oxygen replacement from 2,4-diphenylpyranylium salts, 8, with $\mathrm{N}^{+} \mathrm{R}_{\mathrm{py}}$, just as for 2.6-pyranilium salts (Scheme 14). The yields of products 15 were very good except when $R_{p y}=P h$ (yields: 26-34\%) [38]. 

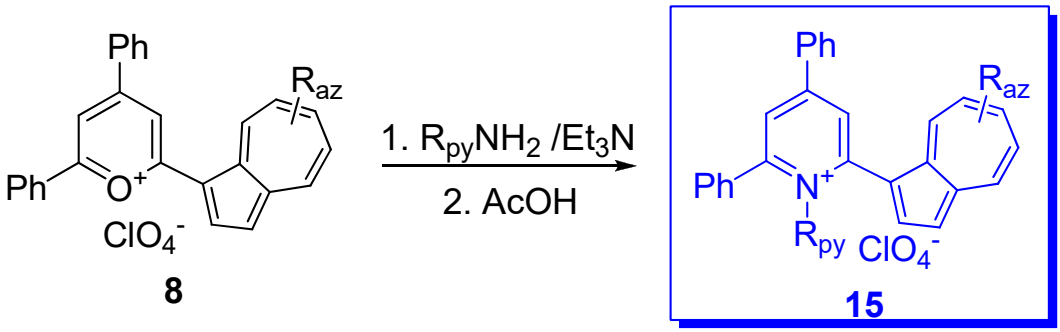

15; $\mathrm{R}_{\mathrm{az}}=\mathrm{H}, 3-\mathrm{Me}, 4,6,8-\mathrm{Me}_{3}, 5-i \mathrm{Pr}, 3,8-\mathrm{Me}_{2}$

$\mathrm{R}_{\mathrm{py}}=i \mathrm{Pr}, \mathrm{Bn}, \mathrm{Ph}$

Scheme 14. Synthesis of 2-(azulen-1-yl)pyridinium salts.

In addition to the research on pyranylium and pyridinium salts with phenyl or methyl at positions 2 and 6, these positions were also replaced by 5-membered heterocycles, thiophen-2-yl and furan-2-yl as shown for compounds 12 and 13 in Scheme 11 [42]. The ability to donate electrons of azulen-1-yl moiety suggested the idea of stabilizing positively charged heteroaromatic compounds, not only with one of this group but with several azulen-1-yl groups. Because the attempts to obtain 2,4,6-tri(azulen-1-yl)pyranylium salts were unsuccessful, attention was directed to the synthesis of some of their vinylogs [43]. Thus, the synthesis started from 2,6-dimethyl-4-(azulen-1-yl)pyranylium salts or from 2,4,6trimethylpyranylium salts which are condensed with azulene-1-carbaldehyde (Scheme 15).
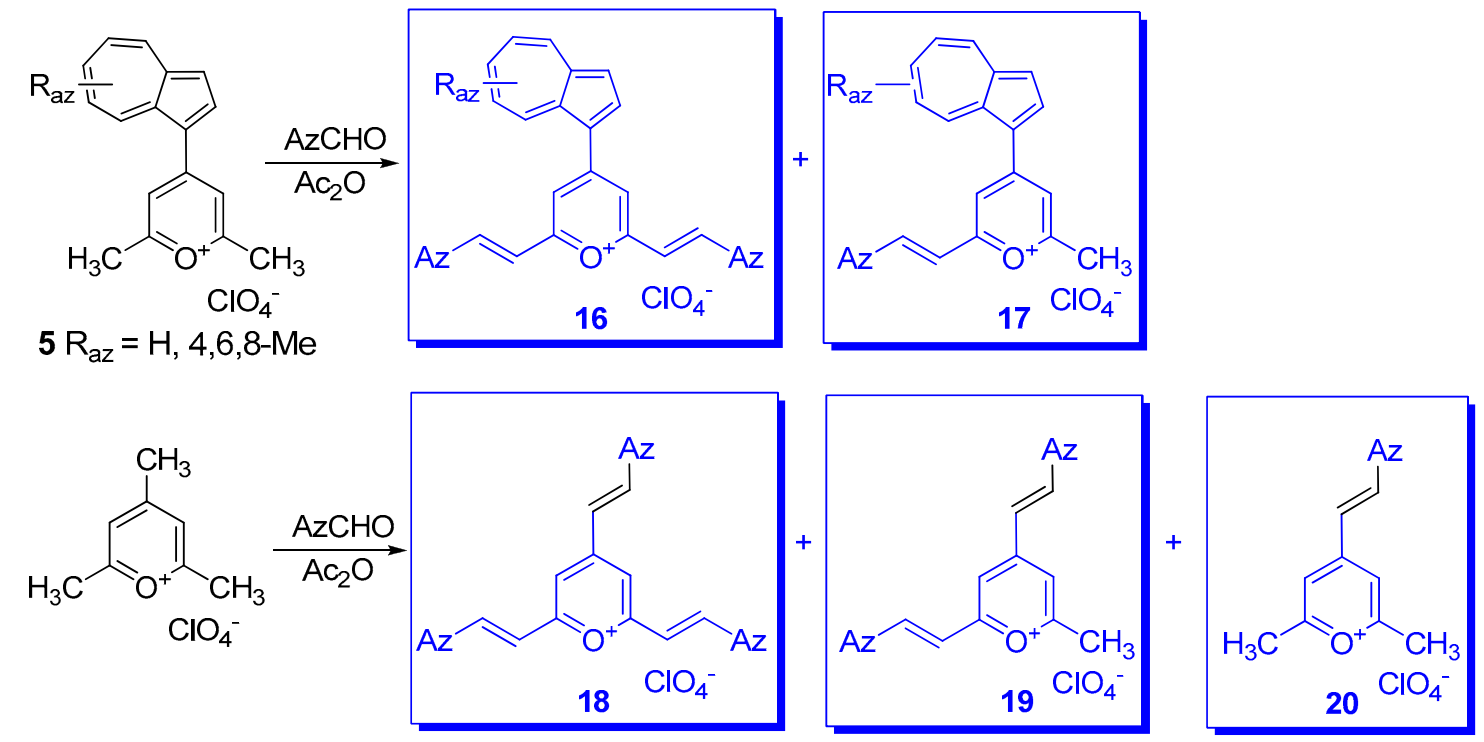

$\mathrm{AzCHO}=$ azulene-1-carbaldehyde with

$\mathrm{R}_{\mathrm{az}}=\mathrm{H}$ or $4,6,8-\mathrm{Me}_{3}$

Scheme 15. Viny-logs of tri(azulen-1-yl)pyranylium salts.

The reaction of salts 5 with azulene-1-carbaldehyde ( $\mathrm{AzCHO})$ occurred in acetic anhydride and a mixture of products $\mathbf{1 6}$ and $\mathbf{1 7}$ resulted, depending on the reaction temperature. At $100{ }^{\circ} \mathrm{C}$ mono condensation generates product $\mathbf{1 7}$ at about $50 \%$ and $\mathbf{1 6}$ resulted in trace, whereas at reflux after bis condensation, the amount of compound $\mathbf{1 6}$ increased to about $45 \%$ and 17 decreased to 5-10\%. A similar behavior was reported when 2,4,6- trimethylpyranylium perchlorate reacted with AzCHO. At $100{ }^{\circ} \mathrm{C}$ only compound 20 resulted, at $160{ }^{\circ} \mathrm{C}$ compound 20 disappears being replaced by compounds 18 and 19, and under microwave irradiation salt 18 remained the only product (50-55\%).

Recently, this class of compounds has been expanded by the generation of 4-(azulen1-yl) pyranylium and pyridinium salts substituted in 2- and 6-positions with 2-(furan-2yl)vinyl, 2-(thiophene-2-yl)vinyl or 2-(3-thienyl)vinyl moieties [44]. 
The distribution of $\pi$ electrons resulting from resonance structures of charged heterocycles substituted in position 4 with azulen-1-yl moiety, shown in Scheme 16, significantly influence the chemical shifts of ${ }^{1} \mathrm{H}$ and ${ }^{13} \mathrm{C}$ in the NMR spectra of both azulene and heterocycle moieties of the salts. Because proton spectra of the studied salts (Table 2) are more suggestive in this regard and provide more valuable information, they will be briefly discussed.

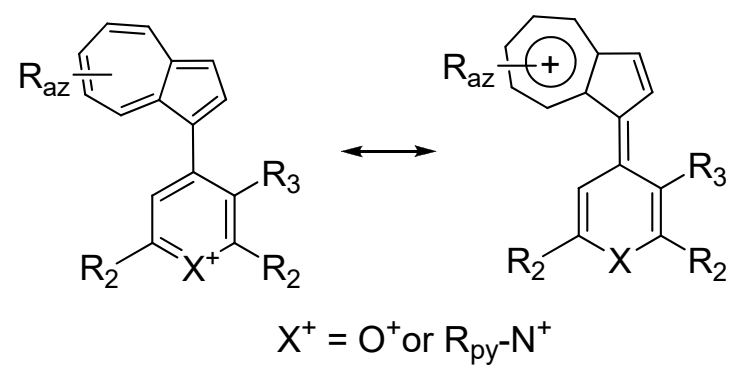

Scheme 16. The most important resonance structures of charged heterocycles.

From Table 2 it can be seen that the good electron-acceptor pyranylium/pyridinium moiety strongly de-shielded all azulenic protons compared with neutral 1-phenylazulene [45] or with 4-(azulen-1-yl)-2,6-diphenylpyridine [41]. On the other hand, the donor-electron contribution of azulene can be highlighted by comparing the chemical shift of protons in the pyranylium ring of compounds 3 and $5(\delta=8.83$ and $8.06 \mathrm{ppm}$, respectively) and for the same protons in 2,4,6-triphenyl-pyranylium perchlorate $(\delta=9.17 \mathrm{ppm})[46,47]$.

The dihedral angle determines the intensity of the push-pull effect between the heterocycle and the aromatic groups as well as the direction of the magnetic fields generated by the heteroaromatic ring current, well reflected in the ${ }^{1} \mathrm{H}-\mathrm{NMR}$ spectra. For this reason, the dihedral angle was calculated [48] for several (azulen-1-yl)heteroaromatic systems and results are included in the Table 3 [37]. The data in the table highlight some features of these systems. The angle for neutral 4-azulen-1-yl-2,6-diphenylpyridine exceeds by $16^{\circ}$ that of corresponding pyridinium salt $10\left(R_{2}=M e ; R_{p y}=n B u ; R_{a z}=R_{3}=H\right)$ attesting the contribution of higher conjugation between the two moieties for salt.

Table 3. Dihedral angle between the azulen-1-yl and the charged heterocycle moiety.

\begin{tabular}{cccc}
\hline Compd. ${ }^{*}$ & $\mathbf{R}_{\mathbf{a z}}$ & $\mathbf{R}_{\mathbf{3}}$ & ${\text { Dihedral Angle (in }{ }^{\circ} \text { ) [48] }}$ \\
\hline \multirow{3}{*}{$\left(\mathrm{R}_{2}=\mathrm{Ph}\right)$} & $\mathrm{H}$ & $\mathrm{H}$ & 24 \\
& $\mathrm{H}$ & $\mathrm{Me}$ & 38 \\
& $2-t \mathrm{Bu}-6-\mathrm{Me}$ & $\mathrm{H}$ & 50 \\
$\mathbf{5}\left(\mathrm{R}_{2}=\mathrm{Me}\right)$ & $\mathrm{H}$ & $\mathrm{H}$ & 22 \\
& $2-t \mathrm{Bu}-6-\mathrm{Me}$ & $\mathrm{H}$ & 45 \\
$\mathbf{1 0}\left(\mathrm{R}_{2}=\mathrm{Me} ;\right.$ & $\mathrm{H}$ & $\mathrm{H}$ & 29 \\
$\left.\mathrm{R}_{\mathrm{py}}=n \mathrm{Bu}\right)$ & $\mathrm{H}$ & $\mathrm{Me}$ & 42 \\
$\mathbf{1 0}\left(\mathrm{R}_{2}=\mathrm{Ph} ; \mathrm{R}_{\mathrm{py}}=\mathrm{Me}\right)$ & $2-t \mathrm{Bu}-6-\mathrm{Me}$ & $\mathrm{H}$ & 54 \\
${ }^{*}$ For 4-azulen-1-yl-2,6-diphenylpyridine the dihedral angle $=45^{\circ}$. & 39
\end{tabular}

The involvement of the charged heteroaromatic moiety decreases from pyranylium to pyridinium salts due to the releasing electron effect, $+\mathrm{I}$, of alkyl substituent at quaternary nitrogen. As a result, the resonance structure with tropylium system Scheme 16 decreases in contribution and so the dihedral angle increases followed by the deshielding of pyridinium protons and the shielding of azulene protons for pyridinium salts $\mathbf{1 0}$ in order of inductive effect of substituent $\mathrm{R}_{\text {py }}$ at $\mathrm{N}^{+}$, namely $i \mathrm{Pr}<n \mathrm{Bu}<\mathrm{Bn}<\mathrm{Ph}$.

Another disturbing factor of the dihedral angle is the occupation of the azulenic position 2 or of position 3(5) of the heterocycle. As an example, the presence of $t \mathrm{Bu}$ at $\mathrm{C} 2$ in salts 3 or 5 with $\mathrm{R}_{\mathrm{Az}}=2-t \mathrm{Bu}, 6-\mathrm{Me}$ shielded azulenic protons and de-shielded pyranylium protons, and the Me in position 3 of pyranylium moiety shields all azulenic protons. 
There are no significant differences between the chemical shifts of azulene protons for the pyranylium and pyridinium salts with thiofen-2-yl or furan-2-yl in 2 and 6-positions, 6, 7, 12 and 13 and those of the corresponding compounds with phenyl in these positions [42].

Without going into details, a remark must be made regarding the influence of the heteroaromatic magnetic field, which exerts influence mainly on the neighboring azulene protons 2, 7 and 8, which are more deshielded [40,41].

As expected, the chemical shifts of carbon atoms belonging to azulene for all salts included in the pyranylium and pyridinium series 3-13 undergo an important deshielding as compared with the reduced effect when azulene is coupled with milder electron withdrawing heterocycles, such as pyridines, thiophene or with phenyl an (effect present especially at C5, C7 and C8a where an increase to 12 ppm was observed for chemical shifts) [37].

With the decrease of push-pull efficiency exerted by the $\pi$-electronic system at the increase in dihedral angle, a bathochromic effect results, observed in UV-Vis spectra in the order: pyridines, pyridinium salts, pyranylium salts $[37,38,40,41]$. The values of $\lambda_{\max }$ (in methanol) for these compounds with $R_{a z}=R_{3}=H ; R_{2}=P h\left(R_{p y}=M e\right)$ are 370, 434 and $530 \mathrm{~nm}$, respectively. The stabilization of tropylium structure by alkylation produces a bathochromic displacement; for example, for pyranylium salts $3\left(R_{a z}=H\right), 3\left(4,6,8-M_{3}\right)$ or $3\left(5-i \mathrm{Pr}, 3,8-\mathrm{Me}_{2}\right) \lambda_{\max }$ increases in the order: 530, 543 and $576 \mathrm{~nm}$. As an interesting observation, for the 2,4,6-tri(azulen-1-ylvinyl) pyranylium salt 18, due to the very large conjugation of the $\pi$-electronic system, $\lambda_{\max }$ reaches a high value, $690 \mathrm{~nm}$ [43].

The research on charged heteroaryls stabilized by azulen-1-yl moieties was recently enlarged with a new class, namely chalco-geno-pyranylium salts with 4-position occupied by azulen-1-yl group [49]. 4-(azulen-1-yl)-2,6-diphenyl-thiopyranylium and 4-(azulen-1yl)-2,6-diphenyl-selenopyrylium perchlorates, 21 and 22 (Scheme 17) were synthesized with good yields on the same route as that used for the corresponding pyranylium salts.

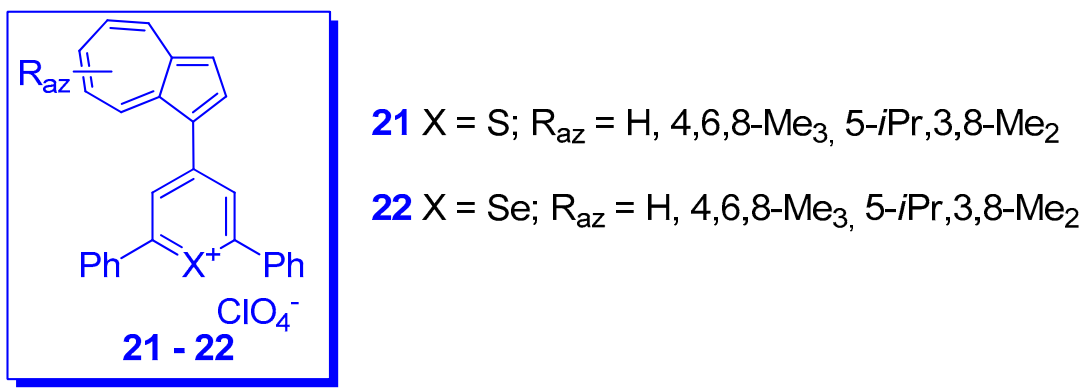

Scheme 17. 4-(Azulen-1-yl)chalco-geno-pyranylium salts.

The lower chalco-geno-pyrylium salts' polarization compared with that for the pyrylium salts is reflected both in UV-Vis spectra as well as in the proton chemical shifts. Thus, the bathochromic effect noticed in order $\mathrm{O}^{+}<\mathrm{S}^{+}<\mathrm{Se}^{+}\left(\lambda_{\max }\right.$ for $3\left(\mathrm{R}_{\mathrm{az}}=\mathrm{R}_{3}=\mathrm{H} ; \mathrm{R}_{2}=\mathrm{Ph}\right)$, $21\left(R_{a z}=H\right.$ and $22\left(R_{a z}=H\right)$ are 530, 572 and 600) could be associated with the decrease in the electronegativity of heteroatom $\left(\mathrm{O}, 3.5 ; \mathrm{S}, 2.5\right.$; Se, 2.4) [50]. The ${ }^{1} \mathrm{H}-\mathrm{NMR}$ spectra of chalco-geno-pyrylium salts show the same characteristics and trends as in the case presented above for pyranylium salts.

\section{Other Systems Stabilized by Azulen-1-yl Moieties}

In this last section reference will be made to some special cases of azulen-1-yl moiety participation in the stability of some carbocations and even of some neutral molecules.

In connection with the stabilization of triarylmethylium ions by at least one azulen1-yl moiety discussed before, the delocalized mono-carbenium ions, salt 23, stabilized by largely conjugate $\pi$ electrons including azulen-1-yl moieties, is presented. Salt 23 was obtained by condensation of all-trans-retinal with azulenes (Scheme 18) [51]. 


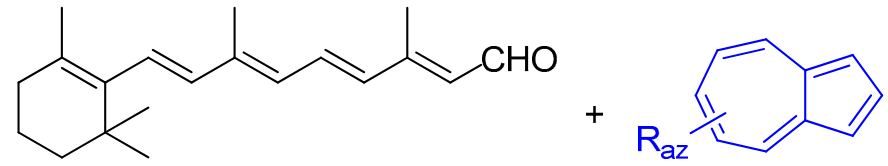

$\mathrm{R}_{\mathrm{az}}=\mathrm{H}$ or $3,8-\mathrm{Me}_{2}, 5-i \mathrm{Pr}$; $\mathrm{HPF}_{6}$ in EtOEt

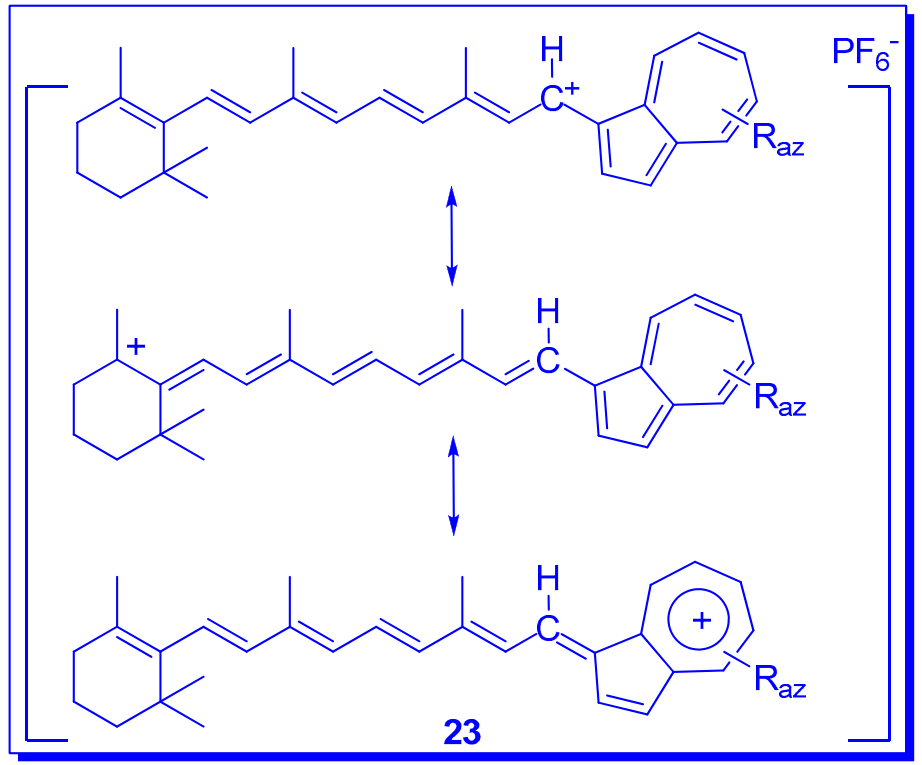

Scheme 18. Condensation of all-trans-retinal with azulenes.

Considering the good electron donor property of both ferrocene and of azulen-1-yls, Farrell et al. [52] used ferrocene-azulenium carbocations and their vinyl-ogs as tetrafluoroborates to investigate a novel series of monometallic monocations, 24n. Starting from formyl ferrocene and azulenes as precursors, the yields of products $24 \mathrm{n}$ were between $58 \%$ and $68 \%$ (Scheme 19).

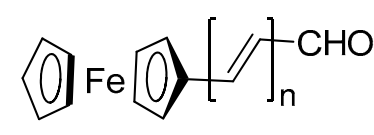

$\mathrm{n}=0-2$

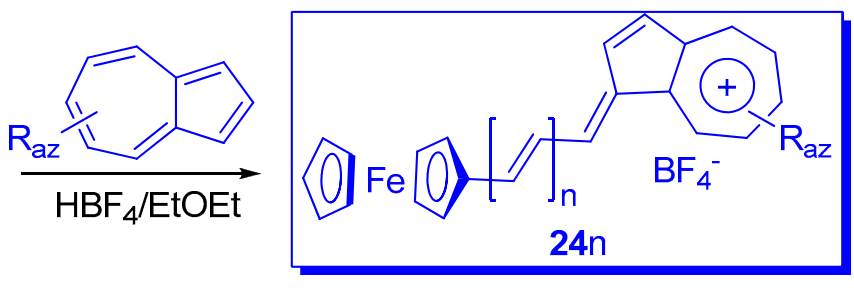

$$
\mathrm{R}_{\mathrm{az}}=\mathrm{H} \text { or } 3,8-\mathrm{Me}_{2}, 5-i \mathrm{Pr}
$$

Scheme 19. Ferrocene-azulenium carbocations.

Contrary to the very low stability of most carbocations with hydrocarbon skeleton, some cyclic cations such as cyclo-propenyl [53] have remarkable stability. In fact, this system is the simplest aromatic Hückel system. The substitution of this cation with three cyclopropyl [54] or three guaiazulene moieties [55] dramatically increases the value of $\mathrm{pK}_{\mathrm{R}+}$ compared with the compound with a three phenyl ring as can be seen in Scheme 20. From the data in Scheme 20 we can see the high difference between the $\mathrm{pK}_{\mathrm{R}+}$ for triphenylmethylium and the tri(azulen-1-yl)methylium cation as compared with the difference between cyclo-propenylium cations $25(\mathrm{R}=\mathrm{Ph})$ and $25(\mathrm{R}=$ guaiazulene-3-yl). The compound 25 ( $R$ = guaiazulene-3-y) was obtained in the Friedel Crafts reaction of $\mathrm{C}_{3} \mathrm{Cl}_{3}+\mathrm{AlC1}_{4}$ 
(prepared from tetra-chloro-cyclo-propene and $\mathrm{AlC}_{3}$ ) with three molar equivalents of guaiazulene in dichloromethane at $-70^{\circ} \mathrm{C}$ [54].

Regarding the azulen-1-yl system contribution to the charge distribution in neutral molecules, without detailing this extensive subject that goes beyond this review, an informative example will be presented below.

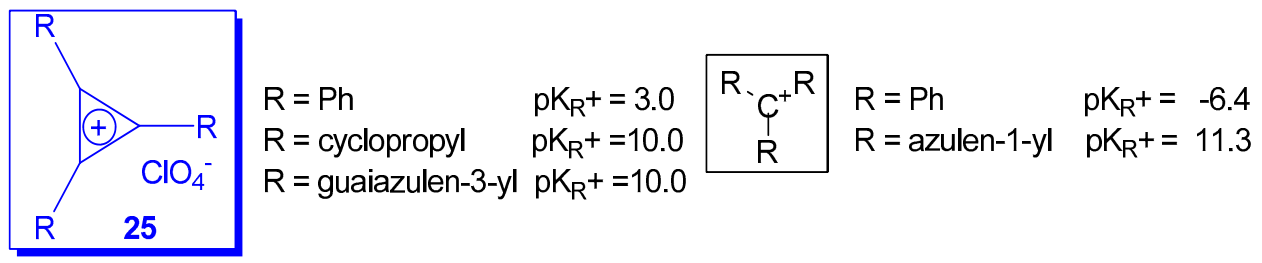

Scheme 20. $\mathrm{pK}_{\mathrm{R}+}$ values for some carbocations with hydrocarbon skeleton.

The azulenyl squarines that will be discussed briefly, already synthesized in 1966 [56], have interested a number of researchers due to the optical properties of the compounds as well as for some biological applications. It should be mentioned that in the over 50 years since the birth of the first azulenyl squarines a huge number of compounds have been reported, some of them being covered by patents and in 2017 a consistent review was published on this topic [57]. The general procedure for obtaining these compounds, 26, is shown in Scheme 21 [58]. The presence of electron-donating groups in an aromatic system employed in a squarine synthesis tends to favor the reaction, and indeed the yield of reactions between azulene and squaric acid proceeds satisfactorily.<smiles>[R12]C1C=CC2=C[CH+]C=C2C=CC1</smiles><smiles></smiles>

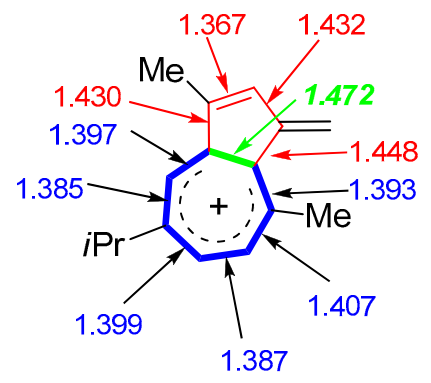

Bond distances (in $\mathrm{A}^{\circ}$ ) in the X-ray crystal structure of compound $26 \mathrm{R}_{\mathrm{az}}=3,8-\mathrm{Me}_{2}, 5-\mathrm{iPr}$

Scheme 21. Azulen-1-yl squarines.

Without going into detail, some information on the structure of the azulenyl squarines is required. The X-ray crystal structure of compound $26\left(\mathrm{R}_{\mathrm{az}}=\mathrm{H}\right.$ or 3,8-Me2, 5-iPr) [57] shows the shorter $\mathrm{C} 1-\mathrm{C} 2$ bond as compared with the other five ring bonds. At the same time, the bond length for six bonds in the big ring are reduced as compared with the distance between the atoms in the five membered ring and the longer azulene bond is between C3a and C8a. (Scheme 21). These observations seem to suggest a more efficient $\pi$-electron conjugation over C3a-C4-C5-C6-C7-C8-C8a than a tropylium structure.

The presence of [18] nulene substructures with $26 \pi$ electrons within the macrocycle is responsible for the aromatic characteristics of porphyrins. According to this model, a large number of other compounds, including some containing azulene systems in the molecule, have been made over time. Lash et al. had the idea of replacing one or more pyrrole rings 
in the porphyrin macrocycle with the five rings of azulene, so edifying a new class of compounds, azuli-porphyrins and related carba-porphyrinoid compounds.

One of the syntheses of azuliporphyrins is based on the application of the " $3+1$ " variant of the MacDonald reaction as can be seen in Scheme 22. Azulene-1,3-dialdehyde was condensed with tri-pyrene in the presence of $\mathrm{HBF}_{4}$ in dichloromethane followed by oxidation with DDQ. The compound 27's porphyrin analogues, due to the participation of the five azulene ring at the stabilization of product, were generated in good yields. A large number of azuli-porphyrins were also obtained by Lash's research team from which only two more examples, 28 and $\mathbf{2 9}$, were selected. In the last compound two azulene moieties were inserted into the molecular structure.<smiles>[R]c1c(Cc2[nH]c(C(=O)O)c([R])c2[R])[nH]c(Cc2[nH]c(C(=O)O)c([R])c2[R])c1[R]</smiles>

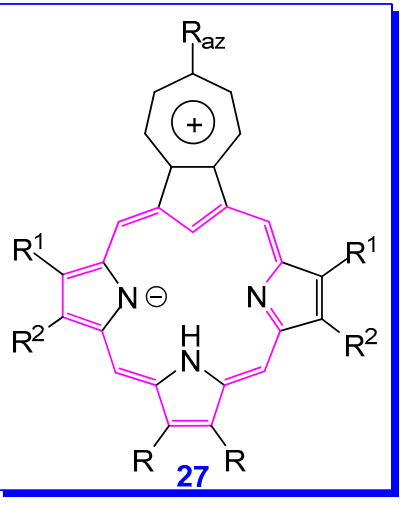

$\mathrm{R}_{\mathrm{az}}=\mathrm{H}, t \mathrm{Bu}, \mathrm{Ph}$

$R^{2}=R^{3}$ or $R^{2} \neq R^{3}$

$R^{2}, R^{3}=M e, E t, P h$
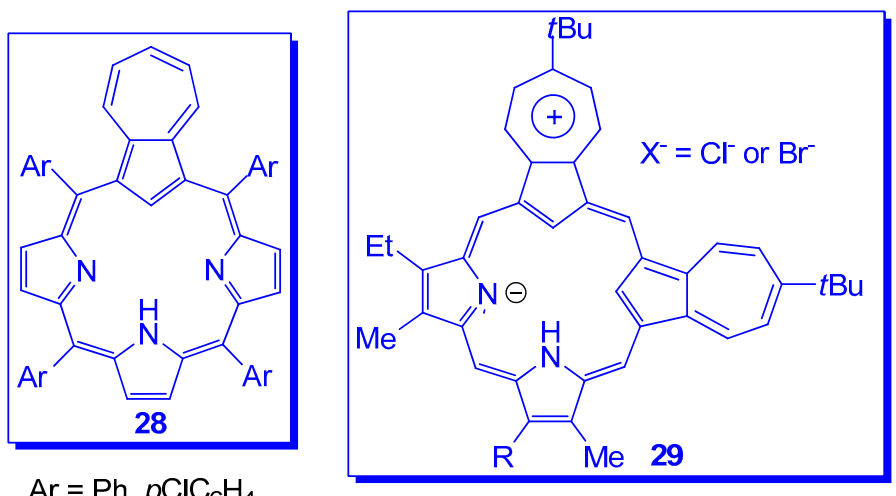

$\mathrm{Ar}=\mathrm{Ph}, p \mathrm{ClC}_{6} \mathrm{H}_{4}$

Scheme 22. Synthesis of azuli-porphyrins.

Finally, and as a curiosity, the attempts to realize a system analog to that of porphyrin, in which the four five-membered rings belong to azulenes will be presented. Starting from the theoretically exciting, if presumed, quatyrin system (Scheme 23), an analog to that of porphyrin, the reparation of calix [4] azulenes, 30, began by reacting azulenes with 
paraformaldehyde in the presence of florisil. However, the realized molecules did not have the desired structure, namely [18] annulene substructures with $26 \pi$ electrons. Using the tetra-aryl compound 31, after oxidation with DDQ and an addition of $\mathrm{HBF}_{4} \cdot \mathrm{Et}_{2} \mathrm{O}$, the tetra-cation 32 was generated. Surprisingly, the chemical shifts in ${ }^{1} \mathrm{H}-\mathrm{NMR}$ spectrum of 32 are consistent with a non-aromatic structure. This finding, as well as the lack of coplanarity of the macrocycle, determined by $\mathrm{X}$-ray spectra, seems to indicate the predominant participation of the structure 32B with the charges located at the four $\mathrm{Csp}^{2}+$, compared to the structure 32A with the tropylium ions. Thus, the macrocyclic aromatic ring current is essentially absent.
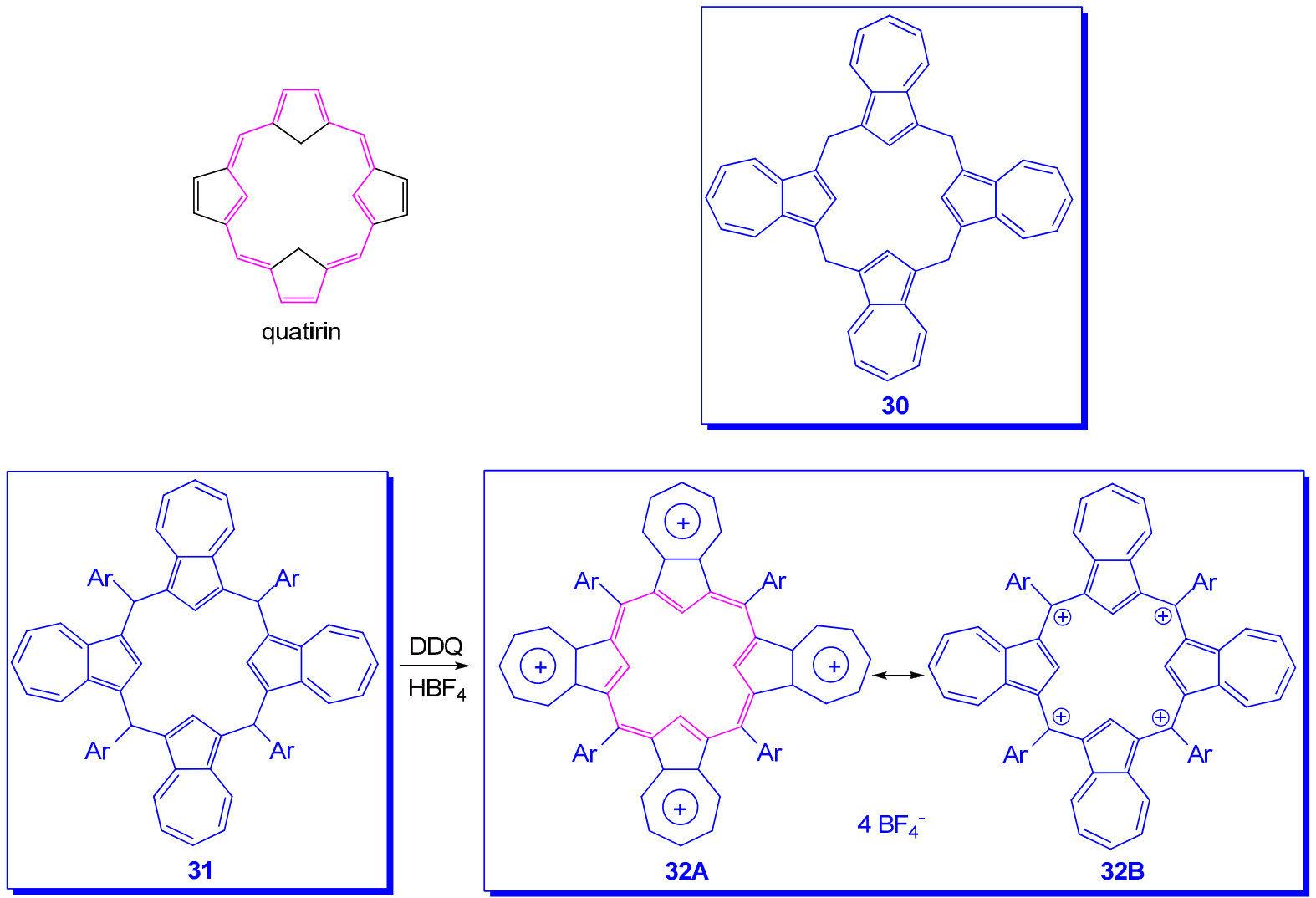

Scheme 23. Macrocycles including azulene moieties.

\section{Conclusions}

Azulenes, those exceptional compounds related to natural derivatives, have a special structure that gives them properties totally different from those of alternating aromatic hydrocarbons and even from the non-alternating ones with which they are related. This paper proposes a brief look at one of the properties of azulenes. The configuration of the $\pi$-electron system over the seven and five azulene rings develops a dipole moment that favors a displacement of the electrons towards an acceptor substituted in position 1 of the azulene. In this way the seven-ring adopts the stable structure of the tropylium ion and consequently stabilizes the entire system in which it is involved. This explains the ease of azulenes in reacting with electrophilic substitutions as well as in donating electrons to acceptor systems. This paper is focused on the donor property of azulene and is limited to the most relevant acceptors, namely methylium ions and positive charged heteroaryls. Several cases of neutral molecules benefiting from azulen-1-yl assistance are also briefly described. It was considered useful to briefly summarize the synthesis of the compounds considered. The change in the charge distribution of the studied systems results in variations in the chemical shifts of protons and carbon atoms in the NMR spectra, as well as in some changes in the UV-Vis spectra. The $\mathrm{pK}_{\mathrm{R}+}$ value of some pseudo-bases, 
such as cations, is a valuable indicator of their stability. The analysis of the mentioned parameters highlights the role of azulene as an electron donor in the stability of the systems in which it is included, especially in those with positive charge. Certainly, this property of azulene will further stimulate the building of chemical systems belonging to a series of areas of theoretical interest but also in those of technical interest, such as dyes and active materials for electronic, optoelectronic and electrochromic devices.

Funding: This research received no external funding.

Institutional Review Board Statement: Not applicable.

Informed Consent Statement: Not applicable.

Data Availability Statement: Data available in a publicly accessible repository.

Acknowledgments: The author is grateful to the late Klaus Hafner from the Institute of Organic Chemistry, Technische Universität Darmstadt for helpful discussions. These discussions were very useful and will be long time remembered.

Conflicts of Interest: The author declare no conflict of interest, financial or otherwise.

\section{References}

1. Solà, M. Forty years of Clar's aromatic $\pi$-sextet rule. Front. Chem. 2013, 1, 22. [CrossRef] [PubMed]

2. Dauben, H.J., Jr.; Bertelli, D.J. Heptalene. J. Am. Chem. Soc. 1961, 83, 4659-4660. [CrossRef]

3. Bally, T.; Chai, S.; Neuenschwander, M.; Zhu, Z. Pentalene: Formation, Electronic, and Vibrational Structure. J. Am. Chem. Soc. 1997, 119, 1869-1875. [CrossRef]

4. Mikheev, Y.A.; Guseva, L.N.; Ershov, Y.A. Nature of the aromaticity of azulene and the dimers responsible for its chromaticity. Russ. J. Phys. Chem. 2012, 86, 1875-1880. [CrossRef]

5. Tobe, Y. Non-Alternant Non-Benzenoid Aromatic Compounds: Past, Present, and Future. Chem. Rec. 2014, 15, 86-96. [CrossRef]

6. Fischer, L.J.; Dutton, A.S.; Winter, A.H. Anomalous effect of non-alternant hydrocarbons on carbocation and carbanion electronic configurations. Chem. Sci. 2017, 8, 4231-4241. [CrossRef] [PubMed]

7. Ito, S.; Morita, N.; Asao, T. Azulene analogues of triphenylmethyl cation; extremely stable hydrocarbon cations. Tetrahedron Lett. 1991, 32, 773-776. [CrossRef]

8. Franke, H.; Muhlstädt, M. Substitution am azulen. Z. Chem. 1962, 2, 275-276. [CrossRef]

9. Franke, H.; Muhlstädt, M. Substitution am azulen. I. J. Prakt. Chem. 1967, 35, 249-261. [CrossRef]

10. Franke, H.; Muhlstädt, M. Substitution am azulen. II. J. Prakt. Chem. 1967, 35, 262-270. [CrossRef]

11. Zeller, K.-P. Houben Weyl, Methoden der Organischen Chemie; G. Thieme Verlag: Stuttgart, Germany; New York, NY, USA, 1985; Volume V/2c, pp. 258-263.

12. Kirby, E.C.; Reid, D.H. Conjugated Cyclic Hydrocarbons and Their Heterocyclic Analogues. The Condensation of Azulenes with Homocyclic and Heterocyclic Aromatic Aldehydes in the Presence of Perchloric Acid. Part II. J. Chem. Soc. 1960, 494-501. [CrossRef]

13. Kirby, E.C.; Reid, D.H. Conjugated Cyclic Hydrocarbons and Their Heterocyclic Analogues. The Condensation of Azulenes with aliphatic aldehydes in the presence of perchloric acid. Part VI. J. Chem. Soc. 1961, 3579-3593. [CrossRef]

14. Hafner, K.; Pelster, H.; Schneider, J. Zur kenntnis der azuleneVII. 1- bzw. 3-alkyliden-azulenium salze. Justus Liebigs Ann. Chem. 1961, 650, 62-80. [CrossRef]

15. Asao, T. Azulenic novel $\pi$-electronic compounds. Pure Appl. Chem. 1990, 62, 507-512. [CrossRef]

16. Ito, S.; Morita, N.; Asao, T. Tris(3,6-di-t-butyl-1-azulenyl)methyl Cation; Hydrocarbon with the highest $\mathrm{pK}_{\mathrm{R}+}$. Tetrahedron Lett. 1994, 35, 751-754. [CrossRef]

17. Ito, S.; Morita, N.; Asao, T. Dynamic stereochemistry of tri(2-methyl-1-azulenyl)methyl cation; steric effect of 2-methyl groups on rotational barriers and mechanism. Tetrahedron Lett. 1994, 35, 3723-3726. [CrossRef]

18. Ito, S.; Fujita, M.; Morita, N.; Asao, T. Synthesis and Dynamic Stereochemistry of Bis(3-methyl-1-azulenyl)(1-naphthyl)methyl Hexafluorophosphate. Clear Evidence of the One-Ring Flip Mechanism of Molecular Propeller by Controlling the Flipping Ring. Chem. Lett. 1995, 475-476. [CrossRef]

19. Ito, S.; Morita, N.; Asao, T. Synthesis and Dynamic Stereochemistry of Tris(2-methyl-1-azulenyl)methyl Cation and the Corresponding Methane Derivative. Evidence That the Conjugative Effect Largely Contributes to the Transition State of the Ring Flipping. Bull. Chem. Soc. Jpn. 1995, 68, 2639-2648. [CrossRef]

20. Ito, S.; Fujita, M.; Morita, N.; Asao, T. Synthesis and Dynamic Stereochemistry of Di-1-azulenyl(1- and 2-naphthyl)methyl Hexafluorophosphates. Clear Evidence of the One-Ring Flip Mechanism of a Molecular Propeller by Controlling the Flipping Ring. Bull. Chem. Soc. Jpn. 1995, 68, 3611-3620. [CrossRef] 
21. Ito, S.; Kikuchi, N.; Morita, N.; Asao, T. Syntheses of Azulene Analogues of Triphenylmethyl Cation: Extremely Stable Hydrocarbon Carbocations and the First Example of a One-Ring Flip as the Threshold Rotation Mechanism for Molecular Propellers. Bull. Chem. Soc. Jpn. 1995, 68, 1409-1436. [CrossRef]

22. Ito, S.; Kikuchi, N.; Morita, N.; Asao, T. The Most Stable Methylcation. Tris(6-methoxy-1-azulenyl)methyl Hexafluorophosphat. Chem. Lett. 1996, 175-176. [CrossRef]

23. Ito, S.; Kikuchi, N.; Morita, N.; Asao, T. Synthesis and Properties of Extremely Stable Tris(6-methoxy-1-azulenyl)methyl Cation and a Series of Di(1-azulenyl)phenylmethyl and (1-Azulenyl)diphenylmethyl Cations Stabilized by Methoxy Substituents. Bull. Chem. Soc. Jpn. 1999, 72, 839-849. [CrossRef]

24. Ito, S.; Kikuchi, N.; Morita, N.; Asao, T. Syntheses and Properties of Extremely Stable Di(1-azulenyl)phenylmethyl and (1Azulenyl)diphenylmethyl Cations Having Dimethylamino Substituents on Their Phenyl Groups. Bull. Chem. Soc. Jpn. 1996, 69, 3225-3237. [CrossRef]

25. Ito, S.; Kikuchi, N.; Morita, N.; Asao, T. Tris[6-(dimethylamino)-1-azulenyl]methyl Hexafluorophosphate. Extremely Stable Methyl Cation with the Highest pKR+Value. J. Org. Chem. 1999, 64, 5815-5821. [CrossRef]

26. Deno, N.C.; Schriesheim, A. Carbonium Ions. II. Linear Free Energy Relationships in Arylcarbonium Ion Equilibria. J. Am. Chem. Soc. 1955, 77, 3051-3054. [CrossRef]

27. Ito, S.; Kikuchi, S.; Okujima, T. Cations and Dications Composed of Two Di(1-azulenyl)methylium Units Connected with 2,5-Thiophenediyl and 2,5-Thienothiophenediyl Spacers. J. Org. Chem. 2001, 66, 2470-2479. [CrossRef] [PubMed]

28. Kikuchi, S.; Iki, M.; Ikeda, C.; Imafuku, K. Synthesis and Properties of (1-Azulenyl)di(3-indolyl)methylium Hexafluorophosphates. Heterocycles 2005, 66, 275-283. [CrossRef]

29. Takekuma, S.; Sasaki, M.; Takekuma, H.; Yamamoto, H. Preparation and Characteristic Properties of 1,4-Bis(3-guaiazulenylmethylium)benze Bishexafluorophosphate. Chem. Lett. 1999, 28, 999-1000. [CrossRef]

30. Ito, S.; Morita, N.; Asao, T. Synthesis, Properties, and Redox Behaviors of Di- and Trications Composed of Di(1-azulenyl)methylium Units Connected byp- andm-Phenylene and 1,3,5-Benzenetriyl Spacers. Bull. Chem. Soc. Jpn. 2000, 73, 1865-1874. [CrossRef]

31. Deuchert, K.; Hünig, S. Multistage Organic Redox Systems-A General Structural Principle. Angew. Chem. Int. Ed. Engl. 1978, 17, 875-886. [CrossRef]

32. Ito, S.; Morita, N.; Asao, T. Syntheses, Properties, and Redox Behaviors of Di(1-azulenyl)ferrocenylmethyl Cations and 1,3-Bis[(1azulenyl)ferrocenylmethylium] azulene Dication. J. Org. Chem. 1996, 61, 5077-5082. [CrossRef]

33. Shoji, T.; Ito, S. The Preparation and Properties of Heteroarylazulenes and Hetero-Fused Azulenes. Adv. Heterocycl. Chem. 2018, 1-54. [CrossRef]

34. Razus, A.C.; Birzan, L. Synthesis of azulenic compounds substituted in the 1-position with heterocycles. Monatsh. Chem. 2018, 150, 139-161. [CrossRef]

35. Krivun, S.V.; Baranov, S.N.; Buryiak, A.I. Introduction of the pyrylium ring into compounds of the aromatic and heterocyclic series. Chem. Heterocycl. Compd. 1971, 7, 1233-1236. [CrossRef]

36. Dorofeenko, G.N.; Koblik, A.V.; Polyakova, T.I.; Murad'yan, L.A. Synthesis of 6-hetaryl-substituted azulenes and their reactions with 2,6-diphenylpyrylium perchlorate. Chem. Heterocycl. Compd. 1980, 16, 807-810. [CrossRef]

37. Razus, A.C.; Birzan, L.; Pavel, C.; Lehadus, O.; Corbu, A.C.; Enache, C. Azulene-substituted Pyranylium Salts. Syntheses and Products Characterization. J. Heterocycl. Chem. 2006, 43, 963-977. [CrossRef]

38. Razus, A.C.; Birzan, L.; Zaharia, O.C. Enache. 2-(Azulen-1-yl)-4,6-diphenyl Substituted Six-membered Heteroaromatics. J. Heterocycl. Chem. 2008, 45, 1139-1147. [CrossRef]

39. Said, S.A.; Fiksdahl, A. Stereoselective transformation of amines via chiral 2,4,6-triphenylpyridinium intermediates. Tetrahedron Asymmetry 2001, 12, 1947-1951. [CrossRef]

40. Razus, A.C.; Birzan, L.; Pavel, C.; Lehadus, O.; Corbu, A.; Chiraleu, F.; Enache, C. Azulene-substituted Pyridines and Pyridinium Salts. 1. Azulene-substituted Pyridinium salts. J. Heterocycl. Chem. 2007, 44, 245-251. [CrossRef]

41. Razus, A.C.; Birzan, L.; Pavel, C.; Lehadus, O.; Corbu, A.; Chiraleu, F.; Enache, C. Azulene-substituted Pyridines and Pyridinium Salts. 2. J. Heterocycl. Chem. 2007, 44, 251-260. [CrossRef]

42. Razus, A.C.; Birzan, L.; Cristea, M.; Tecuceanu, V.; Hanganu, A.; Enache, C. 4-(Azulen-1-yl) six-membered heteroaromatics substituted with thiophen-2-yl or furan-2-yl moieties in 2 and 6 positions. J. Heterocycl. Chem. 2011, 48, 1019-1027. [CrossRef]

43. Razus, A.C.; Cristian, L.; Nica, S.; Zaharia, O.; Hanganu, A. Pyrylium salts with 2-(azulene-1-yl) vinyl substituents in 2-, 4- and/or 6-positions. Arkivoc 2011, 9, 38-50. [CrossRef]

44. Birzan, L.; Cristea, M.; Draghici, C.; Tecuceanu, V.; Hanganu, A.; Ungureanu, E.-M.; Razus, A.C. 4-(Azulen-1-yl) six-membered heteroaromatics substituted in 2- and 6- positions with 2-(2-furyl)vinyl, 2-(2-thienyl)vinyl or 2-(3-thienyl)vinyl moieties. Tetrahedron 2017, 73, 2488-2500. [CrossRef]

45. Dykes, G.; Boruski, S.; Heiermann, J.; Korning, J.; Opwis, K.; Henkel, G.; Kocerling, M. First intermolecular palladium catalyzed arylation of an unfunctionalized aromatic hydrocarbon. J. Organomet. Chem. 2000, 606, 108-110. [CrossRef]

46. Rasala, D.; Bak, T.; Kolehmainen, E.; Styrcz, S.; Gawinecki, R. Transmission of electronic effects in 4-aryl-2, 6-diphenylpyrylium perchlorates and related compounds. J. Phys. Org. Chem. 1996, 9, 631-638. [CrossRef]

47. Detty, M.R.; McKelvey, J.M.; Luss, H.R. Tellurapyrylium dyes. The electron-donating properties of the chalcogen atoms to the chalcogenapyrylium nuclei and their radical dications, neutral radicals, and anions. Organometallics 1988, 7, 1131-1147. [CrossRef] 
48. Takekuma, S.; Mizutani, K.; Inoue, K.; Nakamura, M.; Sasaki, M.; Minematsu, T.; Takekuma, H. Reactions of azulene and guaiazulene with all-trans-retinal and trans-cinnamaldehyde: Comparative studies on spectroscopic, chemical, and electrochemical properties of monocarbenium-ions stabilized by expanded $\pi$-electron systems with an azulenyl or 3-guaiazulenyl group. Tetrahedron 2007, 63, 3882-3893. [CrossRef]

49. Farrell, T.; Meyer-Friedrichsen, T.; Malessa, M.; Haase, D.; Saak, W.; Asselberghs, I.; Wostyn, K.; Clays, K.; Persoons, A.; Heck, J.; et al. Azulenylium and guaiazulenylium cations as novel accepting moieties in e. xtended sesquifulvalene type D-A NLO chromophores. J. Chem. Soc. Dalton Trans. 2001, 29-36. [CrossRef]

50. Kerber, R.C.; Hsu, C.-M. Substituent effects on cyclopropenium ions. J. Am. Chem. Soc. 1973, 95, 3239-3245. [CrossRef]

51. Moss, R.A.; Shen, S.; Krogh-Jespersen, K.; Potenza, J.A.; Schugar, H.J.; Munjal, R.C. Cyclopropyl/phenylcyclopropenyl cations: Studies in stabilization. J. Am. Chem. Soc. 1986, 108, 134-140. [CrossRef]

52. Agranat, I.; Aharon-Shalom, E. Stabilization of Cyclopropenium Ion and Cyclopropenone by Guaiazulene. J. Org. Chem. 1976, 41, 2379-2383. [CrossRef]

53. Sprenger, H.-E.; Ziegenbein, W. Kondensationsprodukte aus Quadratsäure und tertiären aromatischen Aminen. Angew. Chem. 1966, 78, 937-938. [CrossRef]

54. Lynch, D.E.; Hamilton, D.G. The History of Azulenyl Squaraines. Aust. J. Chem. 2017, 70, 857-872. [CrossRef]

55. Pham, W.; Weissleder, R.; Tung, C.-H. An Azulene Dimer as a Near-Infrared Quencher. Angew. Chem. Int. Ed. 2002, 41, 3659-3662. [CrossRef]

56. Lash, T.D. Out of the Blue! Azuliporphyrins and Related Carbaporphyrinoid Systems. Acc. Chem. Res. 2016, 49, 471-482, and the references herein. [CrossRef]

57. Colby, D.A.; Lash, T.D. Calix[4]azulene. J. Org. Chem. 2002, 67, 1031-1033. [CrossRef]

58. Sprutta, N.; Maćkowiak, S.; Kocik, M.; Szterenberg, L.; Lis, T.; Latos-Grażyński, L. Tetraazuliporphyrin Tetracation. Angew. Chem. Int. Ed. 2009, 48, 3337-3341. [CrossRef] 